\title{
A global anthropogenic emission inventory of atmospheric pollutants from sector- and fuel-specific sources (1970-2017): an application of the Community Emissions Data System (CEDS)
}

\author{
Erin E. McDuffie ${ }^{1,2}$, Steven J. Smith ${ }^{3}$, Patrick O'Rourke ${ }^{3}$, Kushal Tibrewal ${ }^{4}$, Chandra Venkataraman ${ }^{4}$, \\ Eloise A. Marais ${ }^{5, a}$, Bo Zheng ${ }^{6}$, Monica Crippa ${ }^{7}$, Michael Brauer ${ }^{8,9}$, and Randall V. Martin ${ }^{2,1}$ \\ ${ }^{1}$ Department of Physics and Atmospheric Science, Dalhousie University, Halifax, NS, Canada \\ ${ }^{2}$ Department of Energy, Environmental, and Chemical Engineering, Washington University in St. Louis, \\ St. Louis, MO, USA \\ ${ }^{3}$ Joint Global Change Research Institute, Pacific Northwest National Laboratory, College Park, MD, USA \\ ${ }^{4}$ Department of Chemical Engineering, Indian Institute of Technology Bombay, Mumbai, Maharashtra, India \\ ${ }^{5}$ School of Physics and Astronomy, University of Leicester, Leicester, UK \\ ${ }^{6}$ Institute of Environment and Ecology, Tsinghua Shenzhen International Graduate School, Tsinghua \\ University, Shenzhen 518055, China \\ ${ }^{7}$ European Commission, Joint Research Centre (JRC), Via E. Fermi 2749 (T.P. 123), 21027 Ispra, Varese, Italy \\ ${ }^{8}$ School of Population and Public Health, University of British Columbia, Vancouver, BC, Canada \\ ${ }^{9}$ Institute for Health Metrics and Evaluation, University of Washington, Seattle, WA, USA \\ ${ }^{a}$ now at: Department of Geography, University College London, London, UK
}

Correspondence: Erin E. McDuffie (erin.mcduffie@wustl.edu)

Received: 27 April 2020 - Discussion started: 3 June 2020

Revised: 4 October 2020 - Accepted: 27 October 2020 - Published: 15 December 2020

\begin{abstract}
Global anthropogenic emission inventories remain vital for understanding the sources of atmospheric pollution and the associated impacts on the environment, human health, and society. Rapid changes in today's society require that these inventories provide contemporary estimates of multiple atmospheric pollutants with both source sector and fuel type information to understand and effectively mitigate future impacts. To fill this need, we have updated the open-source Community Emissions Data System (CEDS) (Hoesly et al., 2019) to develop a new global emission inventory, $\mathrm{CEDS}_{\mathrm{GBD}-\mathrm{MAPS}}$. This inventory includes emissions of seven key atmospheric pollutants $\left(\mathrm{NO}_{x} ; \mathrm{CO} ; \mathrm{SO}_{2} ; \mathrm{NH}_{3}\right.$; non-methane volatile organic compounds, NMVOCs; black carbon, BC; organic carbon, OC) over the time period from 1970-2017 and reports annual country-total emissions as a function of 11 anthropogenic sectors (agriculture; energy generation; industrial processes; on-road and non-road transportation; separate residential, commercial, and other sectors (RCO); waste; solvent use; and international shipping) and four fuel categories (total coal, solid biofuel, the sum of liquid-fuel and natural-gas combustion, and remaining process-level emissions). The $\mathrm{CEDS}_{\mathrm{GBD}-\mathrm{MAPS}}$ inventory additionally includes monthly global gridded $\left(0.5^{\circ} \times 0.5^{\circ}\right)$ emission fluxes for each compound, sector, and fuel type to facilitate their use in earth system models. $\mathrm{CEDS}_{\mathrm{GBD}-\mathrm{MAPS}}$ utilizes updated activity data, updates to the core CEDS default scaling procedure, and modifications to the final procedures for emissions gridding and aggregation. Relative to the previous CEDS inventory (Hoesly et al., 2018), these updates extend the emission estimates from 2014 to 2017 and improve the overall agreement between CEDS and two widely used global bottom-up emission inventories. The
\end{abstract}




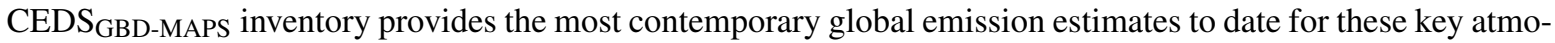
spheric pollutants and is the first to provide global estimates for these species as a function of multiple fuel types and source sectors. Dominant sources of global $\mathrm{NO}_{x}$ and $\mathrm{SO}_{2}$ emissions in 2017 include the combustion of oil, gas, and coal in the energy and industry sectors as well as on-road transportation and international shipping for $\mathrm{NO}_{x}$. Dominant sources of global $\mathrm{CO}$ emissions in 2017 include on-road transportation and residential biofuel combustion. Dominant global sources of carbonaceous aerosol in 2017 include residential biofuel combustion, on-road transportation (BC only), and emissions from the waste sector. Global emissions of $\mathrm{NO}_{x}, \mathrm{SO}_{2}, \mathrm{CO}, \mathrm{BC}$, and $\mathrm{OC}$ all peak in 2012 or earlier, with more recent emission reductions driven by large changes in emissions from China, North America, and Europe. In contrast, global emissions of $\mathrm{NH}_{3}$ and NMVOCs continuously increase between 1970 and 2017, with agriculture as a major source of global $\mathrm{NH}_{3}$ emissions and solvent use, energy, residential, and the on-road transport sectors as major sources of global NMVOCs. Due to similar development methods and underlying datasets, the $\mathrm{CEDS}_{\mathrm{GBD}-\mathrm{MAPS}}$ emissions are expected to have consistent sources

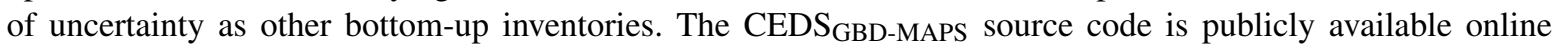
through GitHub: https://github.com/emcduffie/CEDS/tree/CEDS_GBD-MAPS (last access: 1 December 2020). The CEDS $_{\text {GBD-MAPS }}$ emission inventory dataset (both annual country-total and monthly global gridded files) is publicly available under https://doi.org/10.5281/zenodo.3754964 (McDuffie et al., 2020c).

\section{Introduction}

Human activities emit a complex mixture of chemical compounds into the atmosphere, impacting air quality, the environment, and population health. For instance, direct emissions of nitric oxide (NO) rapidly oxidize to form nitrogen dioxide $\left(\mathrm{NO}_{2}\right)$ and can lead to net ozone $\left(\mathrm{O}_{3}\right)$ production in the presence of sunlight and oxidized volatile organic compounds (VOCs) (e.g., Chameides, 1978; Crutzen, 1970). In addition, direct emissions of particles containing organic carbon (OC) and black carbon (BC) as well as secondary reactions involving gaseous sulfur dioxide $\left(\mathrm{SO}_{2}\right)$, $\mathrm{NO}$, ammonia $\left(\mathrm{NH}_{3}\right)$, and VOCs can lead to atmospheric fine particulate matter less than $2.5 \mu \mathrm{m}$ in diameter $\left(\mathrm{PM}_{2.5}\right)$ (e.g., Mozurkewich, 1993; Jimenez et al., 2009; Saxena and Seigneur, 1987; Brock et al., 2002). $\mathrm{PM}_{2.5}$ concentrations were estimated to account for nearly 3 million deaths worldwide in 2017 (GBD 2017 Risk Factor Collaborators, 2018), while surface $\mathrm{O}_{3}$ concentrations were associated with nearly 500000 deaths in 2017 (GBD 2017 Risk Factor Collaborators, 2018) and significant global crop losses, valued at USD 11 billion in 2000 (USD 2000 ) (Avnery et al., 2011; Ainsworth, 2017). In addition, atmospheric $\mathrm{O}_{3}$ and aerosol both impact earth's radiative budget (e.g., Bond et al., 2013; Haywood and Boucher, 2000; US EPA, 2018). Other pollutants, including carbon monoxide (CO), $\mathrm{NO}_{2}$, and $\mathrm{SO}_{2}$, are also directly hazardous to human health (US EPA, 2018), while $\mathrm{NO}_{2}$ and $\mathrm{SO}_{2}$ can additionally contribute to acid rain (Saxena and Seigneur, 1987; US EPA, 2018) and indirectly impact human health via their contributions to secondary $\mathrm{PM}_{2.5}$ formation. In addition, $\mathrm{NH}_{3}$ deposition and nitrification can also cause nutrient imbalances and eutrophication in terrestrial and marine ecosystems (e.g., Behera et al., 2013; Stevens et al., 2004). While these reactive gases and aerosol have both anthropogenic and natural sources, domi- nant global sources of $\mathrm{NO}_{x}\left(=\mathrm{NO}+\mathrm{NO}_{2}\right), \mathrm{SO}_{2}, \mathrm{CO}$, and VOCs include fuel transformation and use in the energy sector, industrial activities, and on-road and off-road transportation (Hoesly et al., 2018). Global $\mathrm{NH}_{3}$ emissions are predominantly from agricultural activities such as animal husbandry and fertilizer application (e.g., Behera et al., 2013), and $\mathrm{OC}$ and $\mathrm{BC}$ have large contributions from incomplete or uncontrolled combustion in residential and commercial settings (e.g., Bond et al., 2013). Emissions of these compounds and the distribution of their chemical products vary spatially and temporally, with atmospheric lifetimes that allow for their transport across political boundaries, continuously driving changes in the composition of the global atmosphere.

Global emission inventories of these major atmospheric pollutants, with both sectoral and fuel type information, are paramount (1) for understanding the range of emission impacts on the environment and human health and (2) for developing effective strategies for pollution mitigation. For example, spatially gridded emission inventories are used as inputs in general circulation climate (GCM) and chemical transport models (CTM), which are used to predict the evolution of atmospheric constituents over space and time. By perturbing emission sources or historical emission trends, such models can quantify the impact of emissions on the environment, economy, and human health (e.g., Mauzerall et al., 2005; Lelieveld et al., 2019; IPCC, 2013; Liang et al., 2018; Lacey and Henze, 2015); provide mitigation-relevant information for polluted regions (e.g., GBD MAPS Working Group, 2016, 2018; RAQC, 2019; Lacey et al., 2017); and anchor future projections (e.g., Shindell and Smith, 2019; Venkataraman et al., 2018; Gidden et al., 2019; Mickley et al., 2004).

Three global emission inventories have been widely used for these purposes, including the Emissions Database for 
Global Atmospheric Research (EDGAR) from the European Commission Joint Research Centre (Crippa et al., 2018), the ECLIPSE (Evaluating the Climate and Air Quality Impacts of Short-Lived Pollutants) inventory from the Greenhouse Gas-Air Pollution Interactions and Synergies (GAINS) model at the International Institute for Applied Systems Analysis (IIASA) (Amann et al., 2011; Klimont et al., 2017), and the CEDS (v2016-07-26) inventory from the newly developed Community Emissions Data System (CEDS) from the Joint Global Change Research Institute at the Pacific Northwest National Laboratory and University of Maryland (Hoesly et al., 2018). All three inventories are derived using a bottom-up approach where emissions are estimated using reported activity data (e.g., amount of fuel consumed) and source- and region-specific (where available) emission factors (mass of emitted pollutant per mass of fuel consumed) for each emitted compound. All three inventories are similar in that they use this bottom-up approach to provide historical, source-specific gridded emission estimates of major atmospheric pollutants $\left(\mathrm{NO}_{x}\left(\right.\right.$ as $\left.\mathrm{NO}_{2}\right) ; \mathrm{SO}_{2}$; $\mathrm{CO}$; non-methane volatile organic compounds, NMVOCs; $\mathrm{NH}_{3}$; $\mathrm{BC}$; and $\left.\mathrm{OC}\right)$. Table 1 provides a comparison of the key features between these inventories, which provide emissions from multiple source sectors over the collective time period from 1750-2014. In contrast to EDGAR and GAINS, the CEDS system implements an increasingly utilized mosaic approach, which, in this case, incorporates activity and emission input data from other sources such as EDGAR, GAINS, and regional- and national-level inventories to produce global emissions that are both historically consistent and reflective of contemporary country-level estimates (Hoesly et al., 2018). The CEDS source code has been publicly released (https://github.com/JGCRI/CEDS/tree/master, last access: 1 December 2020), increasing both the reproducibility and public accessibility to quality emission estimates of global- and national-level air pollutants.

Due to the long development times of global bottomup inventories, current versions of the EDGAR, ECLIPSE, and CEDS inventories are limited in their ability to capture emission trends over recent years (Table 1), particularly the last 6-10 years in regions undergoing rapid change such as China, North America, Europe, India, and Africa. For example, China implemented the Action Plan on the Prevention and Control of Air Pollution in 2013, which has targeted specific emission sectors, fuels, and species and resulted in reductions in ambient $\mathrm{PM}_{2.5}$ concentrations by up to $40 \%$ in metropolitan regions between 2013 and 2017 (reviewed in Zheng et al., 2018). Similarly, over the past 1020 years in the US and Europe, the reduction in coal-fired power plant emissions and phase-in of stricter vehicle emission standards have resulted in emission reductions in $\mathrm{SO}_{2}$ and $\mathrm{NO}_{x}$ across these regions (Krotkov et al., 2016; Duncan et al., 2013; Castellanos and Boersma, 2012; de Gouw et al., 2014). Over this same time period, however, oil and gas production in key regions in the US has more than tripled be- tween 2007 and 2017 (EIA, 2020). In addition, the absence of widespread regulations targeting $\mathrm{NH}_{3}$ from agricultural practices has led to continuous increases in global $\mathrm{NH}_{3}$ emissions (Behera et al., 2013). Global energy consumption also increased by an average of $1.5 \%$ each year between 2008 and 2018 (BP, 2019), and the global consumption of coal increased for the first time in 2017 since its peak in 2013 (BP, 2019). Many of these energy changes have been attributed to the growth of energy generation in rapidly growing regions, such as India (BP, 2019). Africa is also experiencing rapid growth, with increasing emissions from diffuse and inefficient combustion sources, which may not be accurately accounted for in current global inventories (Marais and Wiedinmyer, 2016). Therefore, to capture recent trends around the globe as well as quantify the resulting economic, health, and environmental impacts and mitigate future burdens, computational models require emission inventories with regionally accurate estimates, global coverage, and the most up-to-date information possible. Though global bottom-up inventories can lag in time due to data collection and reporting requirements, the incorporation of smaller regional inventories provides the opportunity to improve the timeliness and regional accuracy of global estimates.

To further increase the policy relevance of such data, it is also important that global emission inventories not only provide contemporary estimates but report emissions as a function of detailed source sector and fuel type. For example, the recent air quality policies in China have included emission reductions targeting coal-fired power plants within the larger energy generation sector (e.g., Zheng et al., 2018). Decisions to implement such policies require accurate predictions of the air quality benefits, which in turn depend on simulations that use accurate estimates of contemporary sector- and fuel-specific emissions. While the EDGAR, ECLIPSE, and CEDS inventories all provide varying degrees of sectoral information (Table 1), there are no global inventories to date that provide public datasets of multiple atmospheric pollutants with both detailed source sector and fuel type information. Crippa et al. (2019) do describe estimates of biofuel use from the residential sector in Europe using emissions from the EDGAR v4.3.2 inventory (EC-JRC, 2018) but do not report global estimates or regional emissions from other fuel types. Similarly, Hoesly et al. (2018) describe fuel-specific activity data and emission factors used to develop the global CEDS v2016-07-26 inventory but do not publicly report final global emissions as a function of fuel type. In contrast, a limited number of regional inventories have provided both fueland sector-specific emissions. These inventories, for example, have been applied to earth system models to attribute the mortality associated with outdoor air pollution to dominant sources of ambient $\mathrm{PM}_{2.5}$ mass, such as residential biofuel combustion in India and coal combustion in China (GBD MAPS Working Group, 2018, 2016). As countries undergo rapid changes that impact fluxes of their emitted pollutants, including population, emission capture technologies, and the 
Table 1. Comparison of three historical, gridded, source-specific emission inventories of atmospheric pollutants $\left(\mathrm{NO}_{x}, \mathrm{SO}_{2}, \mathrm{CO}, \mathrm{NMVOCs}\right.$ $\left.\mathrm{NH}_{3}, \mathrm{BC}, \mathrm{OC}\right)$.

\begin{tabular}{|c|c|c|c|c|c|}
\hline $\begin{array}{l}\text { Inventory name } \\
\text { (version) }\end{array}$ & $\begin{array}{l}\text { Temporal } \\
\text { coverage }\end{array}$ & $\begin{array}{r}\text { Number of reported } \\
\text { gridded sectors }\end{array}$ & $\begin{array}{l}\text { Detailed } \\
\text { fuels }\end{array}$ & $\begin{array}{l}\text { Spatial } \\
\text { resolution }\end{array}$ & Reference \\
\hline CEDS (v2016_07_26) & $1750-2014$ & 9 & Total only & $0.5^{\circ} \times 0.5^{\circ}$ & Hoesly et al. (2018) \\
\hline EDGAR (v4.3.2) & 1970-2012 & 26 & Biofuel (Europe only) ${ }^{b}$ & $0.1^{\circ} \times 0.1^{\circ}$ & Crippa et al. (2018) \\
\hline ECLIPSE (v5a) & $\begin{array}{l}\text { 1990, 1995, 2000, 2005, } 2010 \\
(\text { projections to 2050) }\end{array}$ & 8 & Total only & $0.5^{\circ} \times 0.5^{\circ}$ & $\begin{array}{l}\text { Klimont et al. (2017), Amann et } \\
\text { al. (2011) }\end{array}$ \\
\hline
\end{tabular}

a Projections assume current air pollution legislation (CLE) in the GAINS model. ${ }^{b}$ Described in Crippa et al. (2019).

mix of fuels used, fuel- and source-specific estimates are vital for capturing these contemporary changes and understanding the air quality impacts across multiple scales.

As part of the Global Burden of Disease - Major Air Pollution Sources (GBD-MAPS) project, which aims to quantify the disease burden associated with dominant country-specific sources of ambient $\mathrm{PM}_{2.5}$ mass (https://sites.wustl.edu/acag/ datasets/gbd-maps/, last access: 1 December 2020), we have updated and utilized the CEDS open-source emissions system to produce a new global anthropogenic emission inven-

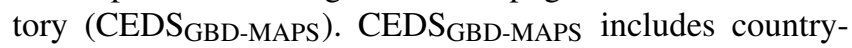
level and global gridded $\left(0.5^{\circ} \times 0.5^{\circ}\right)$ emissions of seven major atmospheric pollutants $\left(\mathrm{NO}_{x}\right.$ (as $\left.\mathrm{NO}_{2}\right), \mathrm{CO}, \mathrm{NH}_{3}$, $\mathrm{SO}_{2}$, NMVOCs, $\mathrm{BC}, \mathrm{OC}$ ) as a function of 11 detailed emission source sectors (agriculture, energy generation, industry, on-road transportation, non-road and off-road transportation, residential energy combustion, commercial combustion, other combustion, solvent use, waste, and international shipping) and four fuel groups (emissions from the combustion of total coal, solid biofuel, liquid fuels and natural gas, plus all remaining process-level emissions) for the time period between 1970-2017. Similar to the prior CEDS inventory released for CMIP6 (Hoesly et al., 2018), CEDS ${ }_{\text {GBD-MAPS pro- }}$ vides surface-level emissions from all sectors, including fertilized soils, but does not include emissions from open burning. In the first two sections we provide an overview of the $\mathrm{CEDS}_{\mathrm{GBD}-\mathrm{MAPS}}$ system and describe the updates that have allowed for the extension to the year 2017 and the added fuel type information. These include updates to the underlying activity data and input emission inventories used for default estimates and scaling procedures (including the use of two new inventories from Africa and India), the additional scaling of default $\mathrm{BC}$ and $\mathrm{OC}$ emissions, the use of updated spatial gridding proxies, and adjustments to the final gridding and aggregation steps that retain detailed sub-sector and fuel type information. The third section presents global CEDS $_{\text {GBD-MAPS }}$ emissions in 2017 and discusses historical trends as a function of compound, sector, fuel type, and world region. The final section provides a comparison of the global CEDS $_{\text {GBD-MAPS }}$ emissions with other global inventories as well as a discussion of the magnitude and sources of uncertainty associated with the $\mathrm{CEDS}_{\mathrm{GBD}-\mathrm{MAPS}}$ products.

\section{Methods}

The 23 December 2019 full release of the Community Emissions Data System (Hoesly et al., 2019) provides the core system framework for the development of the contemporary $\mathrm{CEDS}_{\mathrm{GBD}-\mathrm{MAPS}}$ inventory. The $\mathrm{CEDS}_{\mathrm{GBD}-\mathrm{MAPS}}$ inventory is developed for the GBD-MAPS project and is not an updated release of the core CEDS emissions inventory. As detailed in Hoesly et al. (2018), the original version of the CEDS system was used to produce the first CEDS v2016-07-26 inventory (hereafter called CEDS Hoesly) (CEDS, 2017a, b), which provides global gridded $\left(0.5^{\circ} \times 0.5^{\circ}\right)$ emissions of atmospheric reactive gases $\left(\mathrm{NO}_{x}\left(\right.\right.$ as $\left.\left.\mathrm{NO}_{2}\right), \mathrm{SO}_{2}, \mathrm{NH}_{3}, \mathrm{NMVOCs}, \mathrm{CO}\right)$, carbonaceous aerosol (BC, OC), and greenhouse gases $\left(\mathrm{CO}_{2}\right.$, $\mathrm{CH}_{4}$ ) from eight anthropogenic sectors (agriculture - AGR; transportation - TRA; energy - ENE; industry - IND; residential, commercial, other - RCO; solvents - SLV; waste - WST; international shipping - SHP) over the time period from 1750-2014. Here we provide a brief overview of the Community Emissions Data System with detailed descriptions of the major updates that have been implemented to produce the new CEDS ${ }_{\text {GBD-MAPS }}$ inventory. This inventory has been extended to provide emissions from 19702017 for reactive gases and carbonaceous aerosol $\left(\mathrm{NO}_{x}\right.$, $\mathrm{SO}_{2}, \mathrm{NMVOCs}, \mathrm{NH}_{3}, \mathrm{CO}, \mathrm{BC}, \mathrm{OC}$ ) with increased fuel and sectoral information relative to the $\mathrm{CEDS}_{\mathrm{Hoesly}}$ inventory (Sect. 2.2-2.3). Updates primarily include the use of updated input datasets (Sect. 2.1), new and updated global and regional scaling inventories (Sect. 2.2), added scaling of default BC and OC emissions (Sect. 2.3), and the disaggregation of emissions into contributions from additional source sectors and multiple fuel types (Sect. 2.4).

\subsection{Overview of CEDS GBD-MAPS system}

The CEDS system has five key procedural steps, illustrated in Fig. 1. After the collection of input data in Step 0, Step 1 calculates default global emission estimates (Em) for each chemical compound using a bottom-up approach shown in Eq. (1). In Eq. (1), emissions are calculated using relevant activity $(A)$ and emission factor (EF) data for each country (c) and year (y) as a function of 52 detailed working sectors (s) (sub-sectors used for intermediate steps in the CEDS sys- 
tem) and nine working fuel types (f) (Table 2). CEDS conducts these calculations for two types of emission categories: (1) fuel combustion sources (e.g., electricity production, industrial machinery, on-road transportation, etc.) and (2) process sources (e.g., metal production, chemical industry, manure management, etc.). We note that the distinction between these source categories is reflective of both sector definition and CEDS methodology, as described further in Sect. S2.1 in the Supplement. This results in some working sectors that include emissions from combustion, such as waste incineration and fugitive petroleum and gas emissions, to be characterized in the CEDS system as process-level sources (further details in Sect. S2.1). In contrast to CEDS combustion source emissions, which are calculated in Eq. (1) as a function of eight fuel types, emissions from CEDS process-level sources are combined into a single "process" category, as described in Sect. 2.4. Table 2 provides a complete list of CEDS GBD-MAPS working sectors and fuel types as well as source category distinctions.

$\mathrm{Em}_{\text {species }}^{\text {country, sector, fuel, year }}=A^{\mathrm{c}, \mathrm{s}, \mathrm{f}, \mathrm{y}} \times \mathrm{EF}_{\text {species }}^{\mathrm{c}, \mathrm{s}, \mathrm{f}, \mathrm{y}}$

For emissions from CEDS combustion sources, annual activity drivers in Eq. (1) primarily include country-, fuel-, and sector-specific energy consumption data from the International Energy Agency (IEA, 2019). Sector- and compoundspecific emission factors are typically derived from energy use and total emissions reported from other inventories, including from the GAINS model (Klimont et al., 2017; IIASA, 2014; Amann et al., 2015), Speciated Pollutant Emission Wizard (SPEW) (Bond et al., 2007), and the US National Emissions Inventory (NEI) (NEI, 2013). For international shipping, IEA activity data are supplemented with consumption data and EFs from the International Maritime Organization (IMO), as described in Hoesly et al. (2018) and its supplement. In contrast, default emissions (Em) for CEDS process sources are directly taken from other inventories, including from the EDGAR v4.3.2 global emission inventory (EC-JRC, 2018; Crippa et al., 2018). "Implied emission factors" are then calculated for these process sources in Eq. (1) using global population data (UN, 2019, 2018) or pulp and paper consumption (FAOSTAT, 2015) as the primary activity drivers. For years without available emissions, default estimates for CEDS process sources are calculated in Eq. (1) from a linear interpolation of the "implied emission factors" and available activity data $(A)$ for that year. Supplement Sects. S2.1 and S2.2 provide additional details regarding the input datasets for activity drivers and emission factors used for both CEDS combustion and process source categories.

While CEDS Step 1 is designed to provide a complete set of historical emission estimates, CEDS Step 2 scales these total default emission estimates to existing, authoritative global-, regional-, and national-level inventories. As described in Hoesly et al. (2018), CEDS uses a "mosaic" scaling approach to retain detailed fuel- and sector-specific information across different inventories while maintaining con- sistent methodology over space and time. The development and use of mosaic inventories has been recently increasing as they provide a means to utilize detailed local emissions while harmonizing this information across large regional or global scales (C. Li et al., 2017; Janssens-Maenhout et al., 2015). The CEDS approach, however, differs from previous mosaic inventories (e.g., Janssens-Maenhout et al., 2015), in that local and regional inventories in CEDS GBD-MAPS $_{\text {are }}$ used to scale sectoral emissions at the national level rather than merge together spatially distributed gridded estimates.

The first step in the scaling procedure is to derive a time series of scaling factors (SFs) for each scaling inventory using Eq. (2), calculated as a function of chemical compound, country, sector, and fuel type (where available). Due to persistent differences and uncertainties in the underlying activity data and sectoral definitions in each scaling inventory, CEDS emissions are scaled to total emissions within aggregate scaling sectors (and fuels, where applicable). These aggregate scaling groups are defined for each scaling inventory and are chosen to be broad in order to improve the overlap between CEDS emission estimates and those reported in other inventories. For example, the sum of CEDS emissions from working sectors 1A4a_Commercial-institutional, 1A4b_Residential, and 1A4c_agriculture-forestry-fishing are scaled to the aggregate 1A4_energy-for-buildings sector in the EDGAR v4.3.2 inventory. Sections 2.2 and S2.3 provide further details about this scaling procedure and the scaling inventories used to develop the 1970-2017 CEDS $_{\mathrm{GBD}-\mathrm{MAPS}}$ inventory.

$\mathrm{SF}_{\text {species }}^{\mathrm{c}, \mathrm{s}, \mathrm{f}, \mathrm{y}}=\frac{\text { scaling inventory Em } \mathrm{Em}_{\mathrm{species}}^{\mathrm{c}, \mathrm{s}, \mathrm{f}, \mathrm{y}}}{\text { default CEDS Em }}$

After SFs are calculated in Eq. (2), the second step in the scaling procedure is to extend these SFs forward and backward in time to fill years with missing data. For these time periods, the nearest available SF is applied. If a particular sector or compound is not present in a scaling inventory, default CEDS estimates are not scaled. For BC and OC emissions, the default procedure in the CEDS v2019-12-23 system was to retain all default $\mathrm{BC}$ and $\mathrm{OC}$ emission estimates due to limited availability of historical $\mathrm{BC}$ and $\mathrm{OC}$ emissions. In the CEDS $_{\text {GBD-MAPS }}$ inventory, these species are now scaled to available regional- and national-level inventories (further details in Sect. 2.2). For all other species, the CEDS ${ }_{\text {GBD-MAPS }}$ system uses a sequential scaling methodology where total default emissions for each country are first scaled to available global inventories (primarily EDGAR v4.3.2) and then scaled to regional- and national-level inventories, many of which have been updated in this work (Sect. 2.2 and Table 3). This process results in final CEDS $_{\text {GBD-MAPS }}$ emissions that reflect the inventory last used to scale the emissions for that country (Fig. 2). Figure S2 in the Supplement provides a time series of implied emission factors after the scaling procedure for select sector and fuel combinations that dominate emis- 
Table 2. CEDS sector and fuel type definitions. Aggregate sectors and fuel types in the $\mathrm{CEDS}_{\text {Hoesly }}$ (bold) and CEDS $\mathrm{GBD}_{\mathrm{MAPS}}$ (bold and italic) inventories as well as the system's intermediate gridding sectors (italic) and detailed working sectors and fuel types (consistent between $\mathrm{CEDS}_{\text {Hoesly }}$ and $\mathrm{CEDS}_{\mathrm{GBD}-\mathrm{MAPS}}$ inventories). CEDS working sectors are methodologically treated as two different categories: combustion sectors (c) and "process" sectors (p). As described in the text, combustion sector emissions are calculated as a function of CEDS working fuels, while process emissions are assigned to the single "process" fuel type.

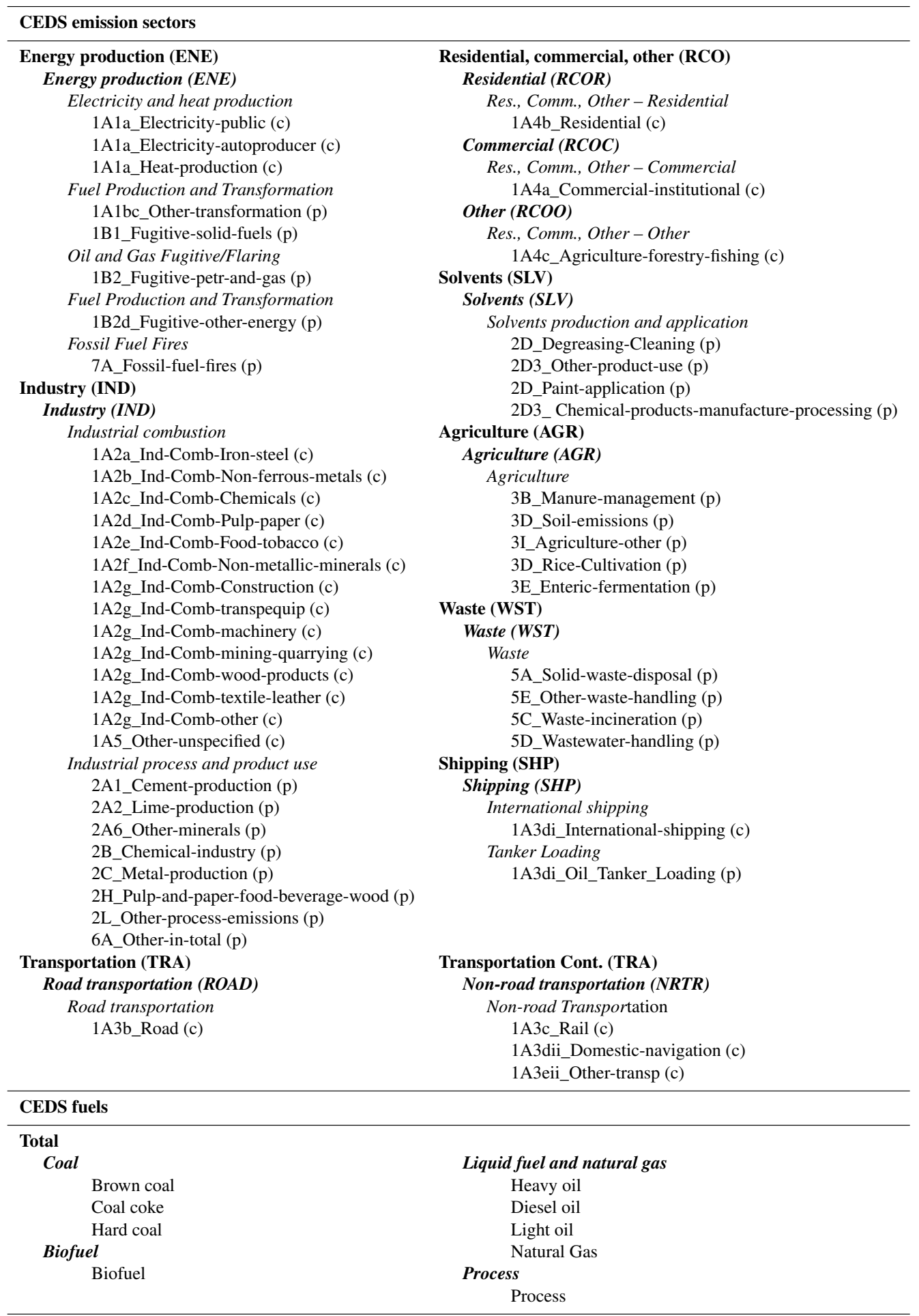


0. Collect input data 1. Calculate default emissions

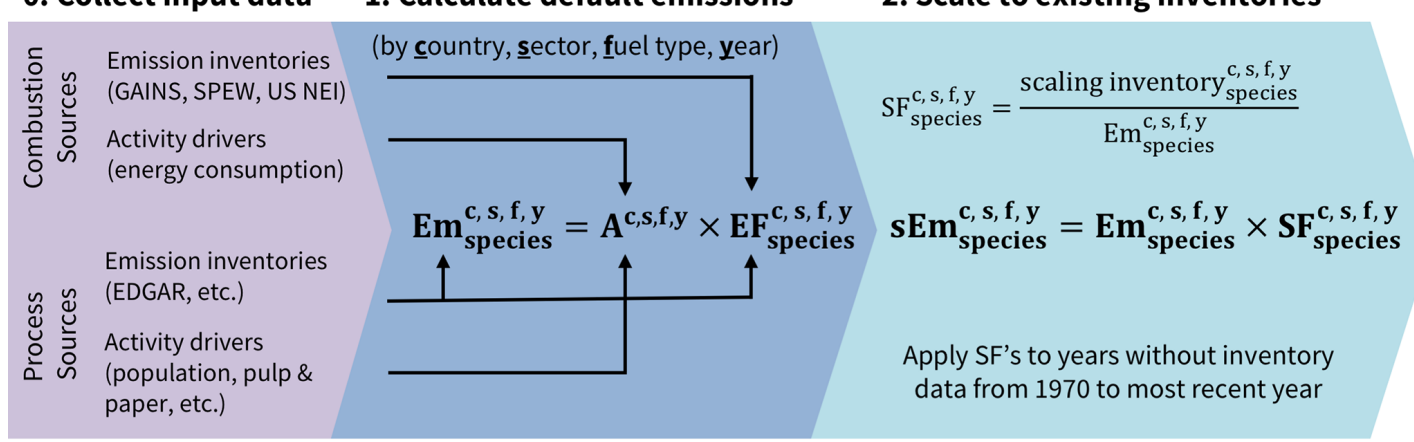

\section{Historical extension}

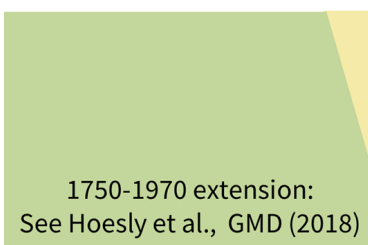
intermediate aggregate sectors (as)

\section{Grid emissions \& final aggregation}

Final emissions at $0.5^{\circ} \times 0.5^{\circ}$ resolution

\section{Aggregate sectors and fuels}

Aggregate scaled emissions to and aggregate fuel types (af)

$$
\begin{aligned}
& \text { Total Em } \mathrm{Em}_{\text {species }}^{\mathrm{c}, \text { as, af, } y}= \\
& \sum^{\text {as }} \sum^{\text {af }} \mathrm{sEm}_{\text {species }}^{\mathrm{c}, \mathrm{s}, \mathrm{f}, \mathrm{y}}
\end{aligned}
$$

(proxies: EDGAR, ECLIPSE, \& population)

$$
\begin{aligned}
& \text { Final Gridded } \mathrm{Em}_{\text {species }}^{\text {as, af, } \mathrm{y}}= \\
& \text { Total Em } \text { species }_{\text {as, af, } y}^{\text {a }} \times \operatorname{Proxy}_{\text {species }}^{\text {as, } y}
\end{aligned}
$$

Aggregate emissions to final sectors and fuels

Figure 1. Default CEDS system summary, adapted from Fig. 1 in Hoesly et al. (2018). Key steps include (0) collecting activity driver ( $A$ ) and emission factor (EF) input data for non-combustion and combustion emission sources; (1) calculating default emissions (Em) as a function of chemical species, country, emission sector, fuel type, and year; (2) calculating scaling factors (SFs) for overlapping years with existing inventories in order to scale default estimates (sEm) and extending SFs for non-overlapping years between 1970-2017 (for earlier emissions, see Hoesly et al., 2018); (4) aggregating scaled emissions to intermediate sectors and fuel types; and (5) using source- and compound-specific spatial proxies to calculate final gridded emissions and aggregate them to the final sectors and fuels. A list of intermediate and final sectors and fuels are in Table 2.

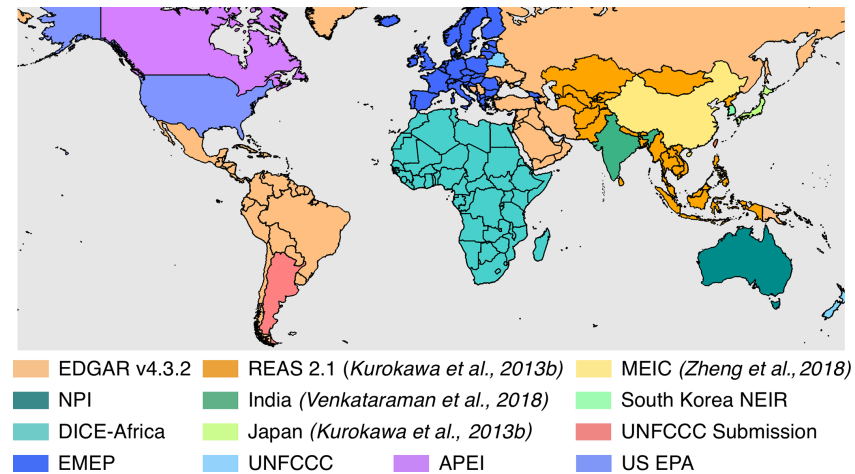

Figure 2. Final scaling inventories used for $\mathrm{CEDS}_{\mathrm{GBD}-\mathrm{MAPS}} \mathrm{NO}_{x}$ emissions; inventory details in Table 3.

sions of each compound in the top 15 emitting countries. Sections 2.2 and $\mathrm{S} 2.3$ describe further details and updates to this scaling procedure.

CEDS Step 3 extends the scaled emission estimates from 1970 back in time to 1750 . This process is necessary as reported emission estimates and energy data are not typically reported with the same level of sectoral and fuel type detail prior to 1970. Hoesly et al. (2018) provide a detailed description of this historical extension procedure, which is used to derive pre-1970 emissions in the CEDS $_{\text {Hoesly inventory. The }}$ new CEDS $_{\mathrm{GBD}-M A P S}$ inventory only reports more contemporary emissions after 1970 and therefore does not utilize this historical extension.

CEDS Step 4 aggregates the scaled country-level CEDS $_{\text {GBD-MAPS }}$ emissions into 17 intermediate gridding sectors (defined in Table 2). In the CEDS v2019-12-23 system, Step 4 additionally aggregated sectoral emissions from all fuel types. In contrast, the CEDS ${ }_{\mathrm{GBD}-\mathrm{MAPS}}$ system retains sectoral emissions from the combustion of total coal (hard coal + coal coke + brown coal), solid biofuel, the sum of liquid oil (light oil + heavy oil + diesel oil) and natural gas, and all CEDS process-level emissions (Table 2). Sections 2.4 and 4.2.4 describe the CEDS $_{\text {GBD-MAPS }}$ fuel-specific emissions in further detail.

Lastly, CEDS Step 5 uses normalized spatial-distribution proxies to allocate annual country-level emission estimates onto a $0.5^{\circ} \times 0.5^{\circ}$ global grid. Annual emissions from the 17 intermediate gridding sectors and four fuel groups are first distributed spatially using compound-, sector-, and year-specific spatial proxies, primarily from the gridded 
Table 3. Scaling inventories.

\begin{tabular}{|c|c|c|c|}
\hline Inventory name & Scaled inventory years & Scaled species & Reference \\
\hline EDGAR v4.3.2 & 1992-2012 & $\mathrm{CO}, \mathrm{NH}_{3}, \mathrm{NMVOCs}, \mathrm{NO}_{x}$ & (EC-JRC, 2018) \\
\hline EMEP NFR14 & 1990-2017 & $\mathrm{CO}, \mathrm{NH}_{3}, \mathrm{NMVOCs}, \mathrm{NO}_{x}, \mathrm{SO}_{2}, \mathrm{BC}$ & EMEP (2019) \\
\hline UNFCCC & 1990-2017 & $\mathrm{CO}, \mathrm{NMVOCs}, \mathrm{NO}_{x}, \mathrm{SO}_{2}$ & UNFCCC (2019) \\
\hline APEI (Canada) & 1990-2017 & $\mathrm{CO}, \mathrm{NH}_{3}, \mathrm{NMVOCs}, \mathrm{NO}_{x}, \mathrm{SO}_{2}$ & ECCC (2019) \\
\hline US EPA & 1970, 1975, 1980, 1985, 1990-2017 & $\mathrm{CO}, \mathrm{NH}_{3}, \mathrm{NMVOCs}, \mathrm{NO}_{x}, \mathrm{SO}_{2}$ & US EPA (2019) \\
\hline MEIC (China) & $2008,2010-2017$ & $\mathrm{CO}, \mathrm{NH}_{3}, \mathrm{NMVOCs}, \mathrm{NO}_{x}, \mathrm{SO}_{2}, \mathrm{BC}, \mathrm{OC}$ & Zheng et al. (2018), C. Li et al. (2017) \\
\hline Japan $^{\mathrm{a}}$ & $1960-2010$ & $\mathrm{CO}, \mathrm{NH}_{3}, \mathrm{NMVOCs}, \mathrm{NO}_{x}, \mathrm{SO}_{2}, \mathrm{BC}, \mathrm{OC}$ & preliminary update from Kurokawa et al. (2013) \\
\hline NEIR (South Korea) ${ }^{\mathrm{a}}$ & 1999-2012 & $\mathrm{CO}, \mathrm{NMVOCs}, \mathrm{NO}_{x}, \mathrm{SO}_{2}$ & $\begin{array}{l}\text { South Korea National Institute of Environmental } \\
\text { Research (2016) }\end{array}$ \\
\hline Taiwan $^{\mathrm{a}}$ & $2003,2006,2010$ & $\mathrm{CO}, \mathrm{NMVOCs}, \mathrm{NO}_{x}, \mathrm{SO}_{2}$ & TEPA (2016) \\
\hline NPI (Australia) & $2000-2017$ & $\mathrm{CO}, \mathrm{NMVOCs}, \mathrm{NO}_{x}, \mathrm{SO}_{2}$ & ADE (2019) \\
\hline DICE-Africa ${ }^{b}$ & 2006,2013 & $\mathrm{CO}, \mathrm{NMVOCs}, \mathrm{NO}_{x}, \mathrm{SO}_{2}, \mathrm{BC}, \mathrm{OC}$ & Marais and Wiedinmyer (2016) \\
\hline SMoG-India ${ }^{b}$ & 2015 & $\mathrm{CO}, \mathrm{NMVOCs}, \mathrm{NO}_{x}, \mathrm{SO}_{2}, \mathrm{BC}, \mathrm{OC}$ & Venkataraman et al. (2018) \\
\hline
\end{tabular}

${ }^{a}$ Not updated from CEDS v2019-12-23; details in Hoesly et al. (2018). ${ }^{b}$ Emissions scaled as a function of sector and fuel type.

EDGAR v4.3.2 inventory. Supplement Table S7 provides a complete list of sector-specific gridding proxies. Details about the general CEDS gridding procedure are provided in Feng et al. (2020), with additional details specific to the CEDS $_{\text {GBD-MAPS }}$ system in Sect. S2.5. Second, gridded emission fluxes (units: $\mathrm{kg} \mathrm{m}^{-2} \mathrm{~s}^{-1}$ ) are aggregated into 11 final sectors (Table 2) and distributed over 12 months using sectoral and spatially explicit monthly fractions from the ECLIPSE project (IIASA, 2015) and EDGAR inventory (international shipping only). Relative to CEDS v201912-23, the new CEDS ${ }_{\text {GBD-MAPS }}$ inventory retains detailed sub-sector emissions from the aggregate RCO (now RCOresidential, RCO-commercial, and RCO-other) and TRA (now on-road and non-road) sectors; separate sectoral emissions from process sources; and combustion sources that utilize coal, solid biofuel, and the sum of liquid fuels and natural gas. Table 2 contains a complete breakdown of the definitions of CEDS working, intermediate gridding, and final sectors. Gridded total NMVOCs are additionally disaggregated into 25 VOC classes following sector- and country-specific VOC speciation maps from the RETRO project (HTAP2, 2013), which are different from those used in the recent EDGAR v4.3.2 inventory (Huang et al., 2017). Similar to the gridding procedure, the same VOC speciation and monthly distributions are applied to sectoral emissions associated with each fuel category.

Final products from the CEDS $_{\text {GBD-MAPS }}$ system include total annual emissions from 1970-2017 for each country as well as monthly global gridded $\left(0.5^{\circ} \times 0.5^{\circ}\right)$ emission fluxes, both as a function of 11 final source sectors and four fuel categories (total coal, solid biofuel, liquid fuel + natural gas, and remaining process sources). Section 5 provides additional details on the dataset availability and file formats.

\subsection{Default emission-scaling procedure - CEDS $S_{\text {GBD-MAPS }}$ update details}

As described above, default emission estimates for each compound are scaled in CEDS Step 2 to existing authoritative inventories as a function of emission sector and fuel type (where available). In the scaling procedure, annual emissions and EFs for each country are first scaled to available global inventories, then to available regional- and national-level inventories, assuming that the latter use local knowledge to derive more accurate regional estimates. Final CEDS $_{\text {GBD-MAPS }}$ emission totals for each country therefore reflect the inventory last used to scale each compound and sector. Many of these inventories are updated annually and, where available, have been updated in this work relative to the CEDS v2019-12-23 system (Table 3). For example, global CEDS $\mathrm{GBD}_{\mathrm{GAPS}}$ combustion source emissions of $\mathrm{NO}_{x}$, total NMVOCs, $\mathrm{CO}$, and $\mathrm{NH}_{3}$ are first scaled to EDGAR v4.3.2 country-level emissions as a means to incorporate additional country-specific information relative to default estimates derived using more regionally aggregate EFs from GAINS. CEDS ${ }_{\text {GBD-MAPS }}$ emissions from European countries are then scaled to available EMEP (European Monitoring and Evaluation Programme) (EMEP, 2019) and UNFCCC (United Nations Framework Convention on Climate Change) (UNFCCC, 2019) inventories that extend to 2017, while $\mathrm{CO}$, NMVOCs, $\mathrm{NO}_{x}$ and $\mathrm{SO}_{2}$ emissions from the US, Canada, and Australia are scaled to emissions that extend to 2017 from the US NEI (US EPA, 2019), Canadian APEI (Air Pollutant Emissions Inventory) (ECCC, 2019), and Australian NPI (National Pollutant Inventory) (ADE, 2019), respectively. In addition, emissions of all seven compounds from China are scaled to emissions for 2008, 2010, and 2012 from C. Li et al. (2017), followed by subsequent scaling to emissions between 2010 and 2017 from Zheng et al. (2018). Relative to the CEDS v2019-12-23 system, regional inventories have also been added to scale $\mathrm{CEDS}_{\mathrm{GBD}-\mathrm{MAPS}}$ emissions 
from India and Africa as described below. Updates to additional regional scaling inventories, including South Korea, Japan, and other European and Asian countries, are not available relative to those used in the CEDS v2019-12-23 system. Table 3 provides a complete list of the inventories used to

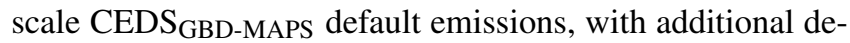
tails in Sect. S2.3.

Relative to the CEDS v2019-12-23 system, the CEDS $_{\text {GBD-MAPS }}$ system adds scaling inventories for two rapidly changing regions, Africa and India. First,

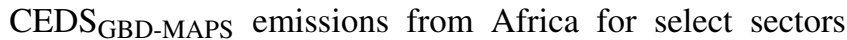
are now scaled to the Diffuse and Inefficient Combustion Emissions in Africa (DICE-Africa) inventory from Marais and Wiedinmyer (2016). This inventory provides gridded $\left(0.1^{\circ} \times 0.1^{\circ}\right)$ emissions for $\mathrm{NO}_{x}\left(=\mathrm{NO}+\mathrm{NO}_{2}\right), \mathrm{SO}_{2}, 25$ speciated VOCs, $\mathrm{NH}_{3}, \mathrm{CO}, \mathrm{BC}$, and $\mathrm{OC}$ for 2006 and 2013 for select anthropogenic sectors and fuels. In this work, default CEDS emissions are scaled to total DICE-Africa emissions from each country and later re-gridded in CEDS Step 5 using source-specific spatial proxies described in Sect. 2.1. Following the CEDS v2019-12-23 scaling procedure (Supplement Sect. S2.3), a set of aggregate scaling sectors and fuels are defined to ensure that $\mathrm{CEDS}_{\mathrm{GBD}}$-MAPS emissions are scaled to emissions from consistent sectors and fuel types within the DICE-Africa inventory (Table S3).

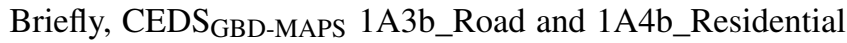
emissions are scaled to DICE-Africa emissions from dieseland gasoline-powered cars and motorcycles as well as biomass and oil combustion associated with residential charcoal, crop residue, fuelwood, and kerosene use. The DICE-Africa inventory also includes emission estimates from gas flares across Africa and ad hoc oil refining in the Niger Delta, fuelwood use for charcoal production and other commercial enterprises, and gas and diesel use in residential generators. Marais and Wiedinmyer (2016) state that these particular sources are missing or not adequately captured in existing global inventories. Therefore, depending on the source sector and inventory details, they recommend that these emissions be added to existing global inventories for formal industry and on-grid energy production in Africa (DICE-Africa, 2016). Due to uncertainties in the representation of these sectors in the default CEDS Africa emissions, these sources are not included in the scaling process here. Default $\mathrm{CEDS}_{\mathrm{GBD}-\mathrm{MAPS}}$ emissions from the 1B2_fugitive_pert_gas (gas flaring) sector (derived from the ECLIPSE and EDGAR inventories) are larger than DICE-Africa gas flaring emissions in 2013, suggesting that this source may be accurately represented in the default

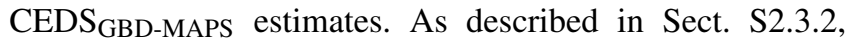
however, residential generator and fuelwood use for charcoal production and other commercial activities are not explicitly represented in CEDS and will be accounted for only to the extent that these sources are included in the underlying IEA activity data and EDGAR process emission estimates. In the event that the DICE-Africa emissions from these sources are missing in the default CEDS estimates, total 2013 $\mathrm{CEDS}_{\mathrm{GBD}-\mathrm{MAPS}}$ emissions from Africa for each compound may be underestimated by up to $11 \%$ (Sect. S2.3, Table S5). These values range from $0.7 \%$ for $\mathrm{SO}_{2}$ to $11 \%$ for $\mathrm{CO}$ (Table S5) and all fall within the range of uncertainties typically reported from regional bottom-up inventories (> 20\%; Sect. 4.2.3). Final emissions from additional sectors or species in CEDS that are not included in the DICE-Africa

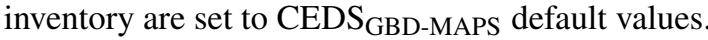

Second, emissions from India for select sectors are now scaled to the Speciated Multi-pollutant Generator Inventory described by Venkataraman et al. (2018) (hereafter called SMoG-India). This inventory includes gridded emissions $\left(0.25^{\circ} \times 0.25^{\circ}\right)$ of $\mathrm{NO}_{x}\left(\right.$ as $\left.\mathrm{NO}_{2}\right), \mathrm{SO}_{2}$, total NMVOCs, $\mathrm{CO}$, $\mathrm{BC}$, and $\mathrm{OC}$ for the year 2015 from select anthropogenic sectors and fuels (SMoG-India, 2019). Similar to DICEAfrica emissions, the final spatial distribution in the SMoGIndia and $\mathrm{CEDS}_{\mathrm{GBD}-\mathrm{MAPS}}$ inventories will differ as countrylevel emissions are scaled to country totals and spatially reallocated using CEDS proxies in Step 5. SMoG-India emissions for each compound are available for 17 sectors and nine fuel types (coal, fuel oil, diesel, gasoline, kerosene, naphtha, gas, biomass, and fugitive or process). Similar to the DICEAfrica inventory, aggregate scaling groups have been defined to scale consistent sectors and fuels between inventories, as described in Sect. S2.3. Briefly, default CEDS $_{\text {GBD-MAPS }}$ emissions for the 1A4c_Agriculture-forestry-fishing sector are scaled to the sum of SMoG-India emissions for agricultural pumps and tractors; 1A4b_Residential emissions are scaled to the sum of SMoG-India emissions from residential lighting, cooking, diesel generator use, and space and water heating; 1A1a electricity and heat generation sectors are scaled to SMoG-India thermal power plant emissions; 1A3b road and rail sectors are scaled to the respective SMoGIndia road and rail emissions; and $\mathrm{CEDS}_{\mathrm{GBD}-\mathrm{MAPS}}$ industrial working sectors are allocated and scaled to four SMoG-India industrial sectors: light industry (e.g., mining and chemical production), heavy industry (e.g., iron and steel production), informal industry (e.g., food production), and brick production. Calculated scaling factors for these sectors are held constant before and after 2015. CEDS ${ }_{\text {GBD-MAPS }}$ emissions do not include contributions from open burning and are not scaled to SMoG-India open burning emissions. In cases where SMoG-India emissions are not reported (e.g., power generation from oil combustion), default $\mathrm{CEDS}_{\mathrm{GBD}-\mathrm{MAPS}}$ emissions are retained. Section $\mathrm{S} 2.3 .3$ provides additional details.

To examine the changes in $\mathrm{CEDS}_{\mathrm{GBD} \text {-MAPS }}$ emissions associated with the incorporation of the SMoG-India and DICE-Africa scaling inventories as well as the updated underlying input datasets, Fig. 3 compares the total and sectoral distribution of $\mathrm{CEDS}_{\mathrm{GBD}-\mathrm{MAPS}}$ and $\mathrm{CEDS}_{\mathrm{Hoesly}}$ emissions for these two regions in 2014 (year with latest overlapping data). For the Africa comparison, panel a in Fig. 3 shows that total $\mathrm{NO}_{x}, \mathrm{BC}$, and $\mathrm{OC}$ emissions are generally 


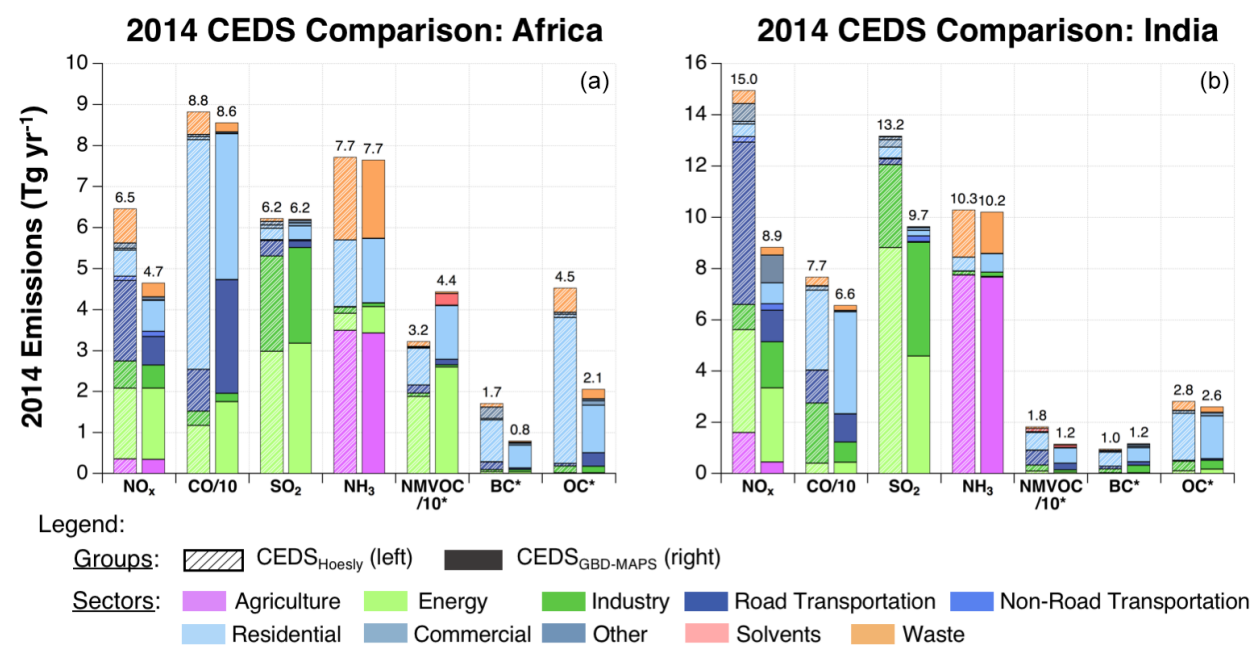

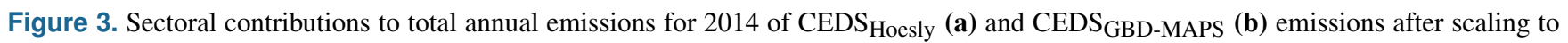
DICE-Africa and SMoG-India regional inventories. The total annual emissions are given by the values above each bar; bar colors represent absolute sectoral contributions to emissions of each chemical compound. CO and NMVOC emissions are divided by 10 for clarity. Stars indicate that NMVOC, $\mathrm{BC}$, and $\mathrm{OC}$ emissions are in units of $\mathrm{TgC}_{\mathrm{yr}}-1 . \mathrm{NO}_{x}$ is in units of $\mathrm{Tg} \mathrm{NO}_{2} \mathrm{yr}^{-1}$.

lower in the CEDS $\mathrm{GBD}_{\text {-MAPS }}$ inventory than in CEDS $\mathrm{S}_{\text {Hoesly }}$. Lower $\mathrm{NO}_{x}$ and $\mathrm{OC}$ emissions are largely associated with smaller contributions from on-road transport and residential combustion, respectively, while lower BC emissions are associated with both lower residential and on-road transport contributions. Lower emissions of $\mathrm{NO}_{x}$ from the transport sector result from the lower EF used for diesel vehicles in the DICE-Africa inventory (Marais et al., 2019). Compared to GAINS (2010) and EDGAR v4.3.2 (2012), on-road emissions from African countries in $\mathrm{CEDS}_{\mathrm{GBD}-\mathrm{MAPS}}$ are up to $2.5 \mathrm{Tg}$ lower for $\mathrm{NO}_{x}$ but within $0.1 \mathrm{Tg}$ for BC. In contrast to $\mathrm{NO}_{x}$, larger EFs in the DICE-Africa inventory for on-road emissions of $\mathrm{CO}$ and $\mathrm{OC}$ result in CEDS $\mathrm{GBD-MAPS}$ emissions from this sector that are up to 14.8 and $0.3 \mathrm{Tg}$ higher than previous estimates. Figure S2 shows that after scaling, the implied emission factors of $\mathrm{CO}$ from oil and gas combustion in the on-road transport sector for four African countries range from $0.19-0.28 \mathrm{~g} \mathrm{~g}^{-1}$, slightly smaller than the range of $0.029-0.380 \mathrm{~g} \mathrm{~g}^{-1}$ used in the DICE-Africa inventory. Emissions from the residential and commercial sectors in Africa are generally lower in CEDS $_{\text {GBD-MAPS }}$ than in $\mathrm{CEDS}_{\text {Hoesly }}$ due to both lower biofuel consumption and a lower assumed EF in the DICE-Africa inventory (Marais and Wiedinmyer, 2016). Residential BC and OC emission estimates are also lower than those from GAINS (Klimont et al., 2017). The difference in biofuel consumption is due to different data sources. The DICE-Africa inventory uses residential wood fuel consumption estimates from the UN, while $\mathrm{CEDS}_{\text {Hoesly }}$ uses data from the IEA. Both of these sources consist largely of estimates for African countries because there is little country-reported biofuel consumption data available. The estimation methodologies for both the UN and IEA estimates are not well documented, which adds to the uncertainty in these values (Sect. 4.2). After scaling, the implied EFs for residential biofuel emissions of OC are $\sim 0.001-0.002 \mathrm{~g} \mathrm{~g}^{-1}$ in three African countries (Fig. S2), within the range of EFs of $0.0007-0.003 \mathrm{~g} \mathrm{~g}^{-1}$ implemented in the DICE-Africa inventory. Total CEDS ${ }_{\text {GBD-MAPS }}$ emissions of NMVOCs are larger, primarily due to increased contributions from solvent use in the energy sector associated with changes in the EDGAR v4.3.2 inventory, while total emissions of $\mathrm{CO}, \mathrm{SO}_{2}$, and $\mathrm{NH}_{3}$ are relatively consistent between the two CEDS versions.

For the India comparison, panel $\mathrm{b}$ of Fig. 3 shows that total emissions of $\mathrm{NO}_{x}, \mathrm{CO}, \mathrm{SO}_{2}, \mathrm{NMVOCs}$, and $\mathrm{OC}$ are lower in CEDS $\mathrm{GBD}_{\text {-MAPS. }}$. Relative reductions in $\mathrm{NO}_{x}$ emissions are largely associated with on-road transport. Scaled CEDS $_{\text {GBD-MAPS }}$ transport emissions are $5 \mathrm{Tg}$ smaller than $\mathrm{NO}_{x}$ emissions in $\mathrm{CEDS}_{\mathrm{Hoesly}}$, largely as a result of lower fuel consumption levels for gas, diesel, and compressed natural gas (CNG) on-road vehicles used to develop SMoG-India estimates (Sadavarte and Venkataraman, 2014). Figure S2 shows that the implied emission factor for $\mathrm{NO}_{x}$ emissions from oil and gas combustion in the on-road transport sector in India is $\sim 0.015 \mathrm{~g} \mathrm{~g}^{-1}$ in 2015 , which falls within the range of values of $0.0026-0.046 \mathrm{~g} \mathrm{~g}^{-1}$ used for various vehicles and fuel type in Venkataraman et al. (2018). Similarly, $\mathrm{NO}_{x}$ transport emissions are also lower in CEDS ${ }_{\text {GBD-MAPS }}$ relative to the EDGAR and GAINS inventories. Causes of other reductions relative to the $\mathrm{CEDS}_{\text {Hoesly }}$ are mixed. For example, lower emissions of $\mathrm{SO}_{2}$ and NMVOCs are largely associated with the energy sector, while reductions in the industry sector contribute to reduced $\mathrm{CO}$ emissions. For $\mathrm{SO}_{2}$, Fig. S2 shows that the implied EF for coal combustion in the energy sector is $\sim 0.004 \mathrm{~g} \mathrm{~g}^{-1}$, slightly lower than the range of $0.0049-0.0073 \mathrm{~g} \mathrm{~g}^{-1}$ used for the SMoG-India inventory. 


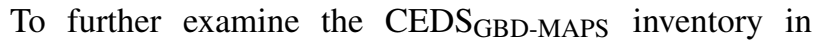
these regions, Fig. 4 compares final $\mathrm{CEDS}_{\mathrm{GBD}-\mathrm{MAPS}}$ and $\mathrm{CEDS}_{\text {Hoesly }}$ emissions for India and Africa to total emissions from two widely used global inventories: GAINS (ECLIPSE v5a) and EDGAR (v4.3.2). First, Fig. 4 shows the percent difference between the CEDS ${ }_{\mathrm{GBD}-M A P S}$ inventory and the GAINS and EDGAR inventories on the $y$ axis against the percent difference between the $\mathrm{CEDS}_{\text {Hoesly }}$ inventory and GAINS and EDGAR emissions on the $x$ axis. Percent differences are calculated from total emissions from Africa (left) and India (right) for the year 2012 for the comparison with EDGAR and for 2010 for the comparison to GAINS (most recent years with overlapping data). The green shaded areas indicate regions where the updated $\mathrm{CEDS}_{\mathrm{GBD}-\mathrm{MAPS}}$ inventory has improved agreement with EDGAR or GAINS rel-

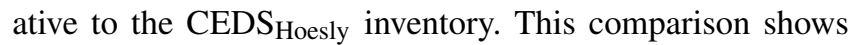
that the additional scaling of CEDS GBD-MAPs $_{\text {emissions to }}$ the SMoG-India inventory generally improves agreement with both the EDGAR and GAINS inventories relative to $\mathrm{CEDS}_{\text {Hoesly }}$ for all species except black carbon (BC). Scaling to the DICE-Africa inventory generally improves CEDS $_{\text {GBD-MAPS }}$ agreement with the EDGAR inventory but not with GAINS (except for OC). Further comparisons to these two inventories are discussed in Sect. 4. While uncertainties in emissions from these inventories are expected to be at least $20 \%$ for each compound (discussed in Sect. 3.3), this comparison provides an illustration of the changes between the two CEDS versions relative to two widely used global inventories.

\subsection{Default BC- and OC-scaling procedure - CEDS $_{\text {GBD-MAPS }}$ update details}

Relative to the CEDS v2019-12-23 system, the secondlargest change to the $\mathrm{CEDS}_{\mathrm{GBD}-\mathrm{MAPS}}$ system is the added scaling of $\mathrm{BC}$ and $\mathrm{OC}$ emissions in CEDS Step 2. In the v2019-12-23 system, OC and BC were not scaled due to a lack of historical $\mathrm{BC}$ and $\mathrm{OC}$ emission estimates in regional and global inventories. Due to the focus of the CEDS $\mathrm{GBD}_{\mathrm{GB}} \mathrm{MAPS}$ inventory on more recent years, these two compounds are now scaled to available regional- and country-level estimates (Table 3 ) following the same scaling procedure described above for the reactive gases. Unlike the reactive gases, however, $\mathrm{BC}$ and $\mathrm{OC}$ emissions are not scaled to the global EDGAR v4.3.2 inventory due to the large reported uncertainties in this inventory (ranging from $46.8 \%$ to $153.2 \%$; Crippa et al., 2018).

To examine the impact of the new $\mathrm{BC}$ and $\mathrm{OC}$ emissions scaling, in addition to the updated IEA energy consumption data, Figs. 5 and S3-S4 show time series of global BC and $\mathrm{OC}$ emissions from CEDS $\mathrm{GBD}_{\mathrm{B}-\mathrm{MAPS}}$ compared to emissions from the $\mathrm{CEDS}_{\text {Hoesly }}$ inventory. In 2014, respective global annual emissions of BC and OC are $21 \%$ and $28 \%$

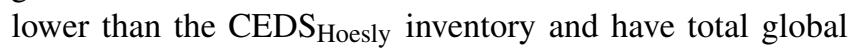
annual emissions in 2017 of 6 and $13 \mathrm{Tg} \mathrm{C} \mathrm{yr}^{-1}$ for $\mathrm{BC}$ and
OC, respectively. These reductions in global emissions are largely due to the added scaling of emissions from China, Africa, Japan, and other countries in Asia included in the REAS inventory (Figs. S3-S4). Figures 5 and S3-S4 additionally compare $\mathrm{CEDS}_{\mathrm{GBD}-\mathrm{MAPS}}$ emissions to those from the GAINS (ECLIPSE v5a) and EDGAR (v4.3.2) inventories, which generally show improved agreement in $\mathrm{BC}$ and OC emissions with the GAINS inventory. CEDS ${ }_{\text {GBD-MAPS }}$ emissions between 1990 and 2015 are now 7\%-14\% lower than GAINS BC emissions, while CEDS $_{\text {GBD-MAPS }}$ emissions of OC remain $12 \%-25 \%$ higher than GAINS estimates. Further discussion of CEDS ${ }_{\mathrm{GBD}-M A P S} \mathrm{BC}$ and $\mathrm{OC}$ emissions and comparisons to EDGAR and GAINS inventories are below in Sect. 4.1.2. As an additional point of comparison, Bond et al. (2013) report global BC and OC values for the year 2000, derived from averages of energy-related burning emissions from SPEW and GAINS. Reported global estimates of BC and $\mathrm{OC}$ are 5 and $\sim 11-14 \mathrm{TgC}$ (16 Tg organic aerosol reported; organic-mass-to-organic-carbon ratio $=1.1-1.4)$, respectively (Bond et al., 2013). These also have improved agreement with the $\mathrm{CEDS}_{\mathrm{GBD}-\mathrm{MAPS}}$ estimates of $\mathrm{BC}$ and $\mathrm{OC}$

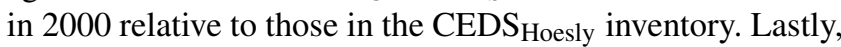
we note plans for an upcoming update to the core CEDS system to improve historical trends in carbonaceous aerosol by incorporating reported inventory values for total $\mathrm{PM}_{2.5}$ and its ratio with $\mathrm{BC}$ and $\mathrm{OC}$ emissions.

\subsection{Fuel-specific emissions - CEDS $S_{\text {GBD-MAPS }}$ update details}

Prior to gridding, CEDS $_{\text {GBD-MAPS }}$ Step 4 combines total country-level emissions for each of the 52 working sectors and nine fuel groups into 17 aggregate sectors and four fuel groups: total coal (hard coal + brown coal + coal coke), solid biofuel, the sum of liquid fuels (heavy oil + light oil + diesel oil) and natural gas, and all remaining "process" emissions (Table 2). In contrast, the CEDS v2019-12-23 system aggregates all fuel-specific emissions and reports inventory values as a function of sector only. In CEDS $_{\mathrm{GBD}-\mathrm{MAPS}}$, countrytotal emissions from these aggregate sectors and fuel groups are distributed across a $0.5^{\circ} \times 0.5^{\circ}$ global grid using spatial gridding proxies, as discussed in Sect. 2.1 (Table S7). During gridding, the same spatial proxies are applied to all fuel groups within each sector. In practice, this requires that the gridding procedure be repeated 4 times for each of the fuel groups. After gridding in CEDS Step 5, both annual countrytotal and gridded emission fluxes from each fuel group are aggregated to 11 final sectors. Figure S5 demonstrates the level of detail available in the new $\mathrm{CEDS}_{\mathrm{GBD}-M A P S}$ gridded emission inventory by illustrating global $\mathrm{BC}$ emissions in 2017 from (1) all source sectors, (2) the residential sector only, (3) residential biofuel use only, and (4) residential coal use only. Additional uncertainties associated with the CEDS $_{\text {GBD-MAPS }}$ fuel-specific emissions in both the country- 

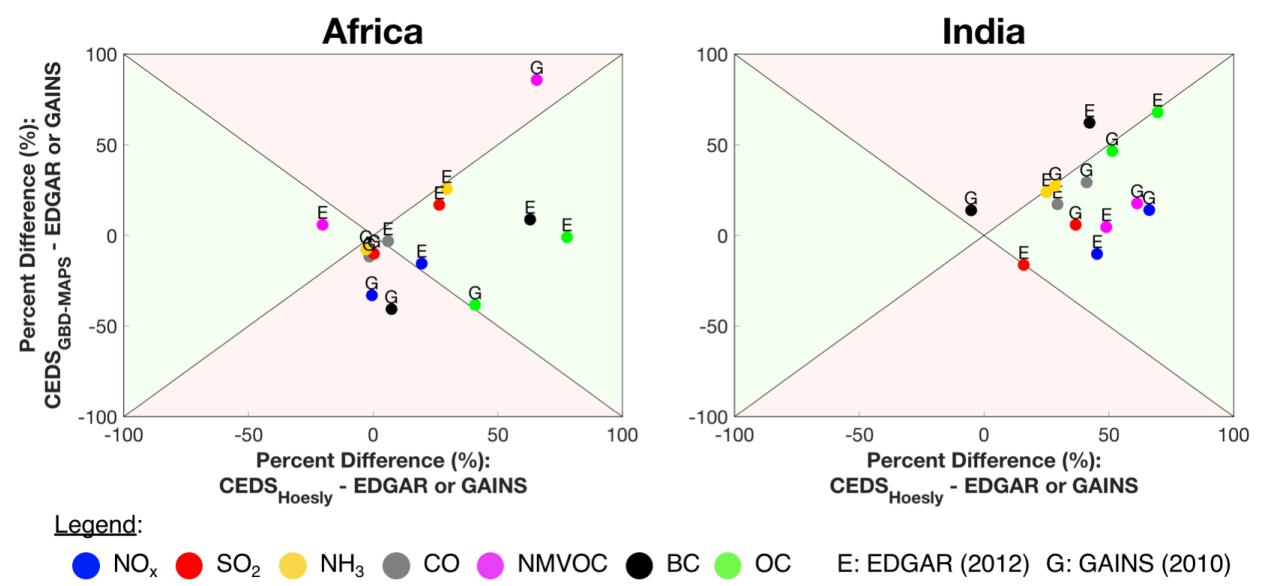

egend:

CEDS $_{\text {Hoesly }}$ - EDGAR or GAINS

$B C \bigcirc \mathrm{OC}$ E: EDGAR (2012) G: GAINS (2010)

Figure 4. The $x$ and $y$ axes show the percent difference between CEDS emissions in India and Africa ( $y$ axis: CEDS axis: $\mathrm{CEDS}_{\text {Hoesly }}$ ) and those from the GAINS (ECLIPSE v5a) and EDGAR v4.3.2 inventories (i.e., $100 \times(\mathrm{CEDS}-\mathrm{EDGAR}) /((\mathrm{CEDS}-$ EDGAR)/2)). Comparisons are conducted with the most recent available year, 2010, for the comparison with GAINS and 2012 for the comparison with EDGAR. Green regions indicate where the $\mathrm{CEDS}_{\mathrm{GBD}-\mathrm{MAPS}}$ emissions have improved agreement with EDGAR and GAINS relative to the $\mathrm{CEDS}_{\text {Hoesly }}$ inventory. Red regions indicate where $\mathrm{CEDS}_{\mathrm{GBD}-\mathrm{MAPS}}$ emissions have worse agreement with EDGAR or GAINS relative to the $\mathrm{CEDS}_{\text {Hoesly }}$ inventory. The color of each point represents the chemical compound, and each point is labeled with an "E" or "G", indicating that the percent difference was calculated using EDGAR or GAINS, respectively.
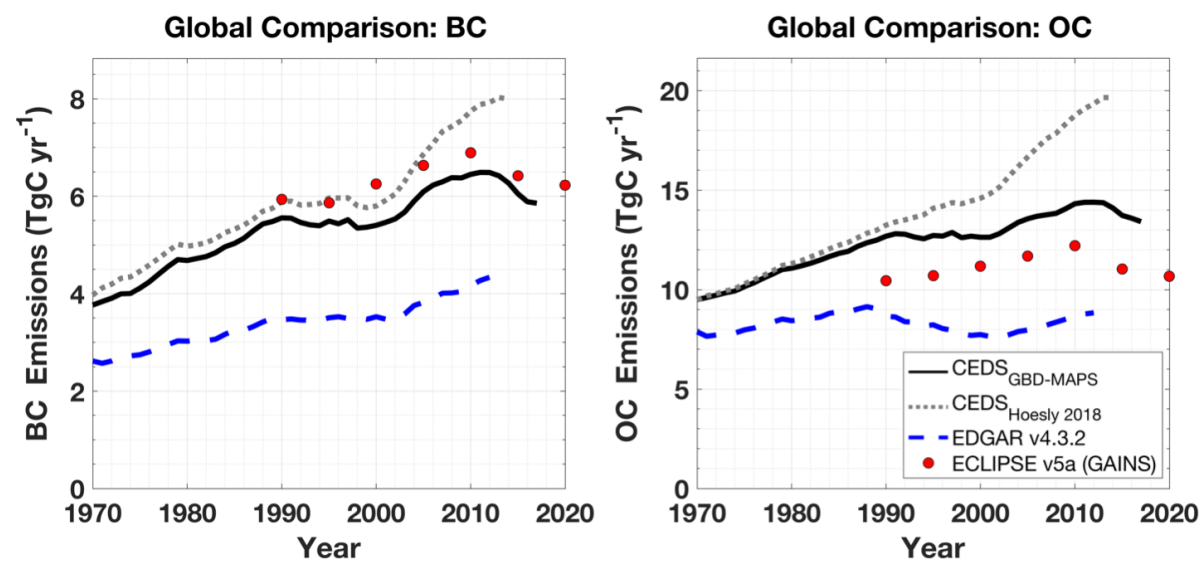

Figure 5. Comparison of global inventories of BC and OC emissions. Total EDGAR v4.3.2 and GAINS (ECLIPSE v5a) emission inventories shown without agricultural waste burning and aviation emissions. EDDS $_{\mathrm{GBD}-\mathrm{MAPS}}$ emissions of BC and OC are not scaled to EDGAR or GAINS estimates.

total and annual gridded products are discussed further in Sect. 4.2.4

\section{Results}

The new $\mathrm{CEDS}_{\mathrm{GBD}-\mathrm{MAPS}}$ inventory provides global emissions of $\mathrm{NO}_{x}, \mathrm{SO}_{2}, \mathrm{NMVOCs}, \mathrm{NH}_{3}, \mathrm{CO}, \mathrm{OC}$, and $\mathrm{BC}$ for 11 anthropogenic sectors (agriculture, energy, industry, onroad, non-road transportation, residential, commercial, other, waste, solvents, international shipping) and four fuel groups (combustion of total coal, solid biofuel, liquid fuels and natural gas, and process sources) over the time period between 1970-2017. Final country-level emissions are provided as annual time series in units of metric kilotons per year $\left(\mathrm{kt} \mathrm{yr}^{-1}\right)$ for each sector and fuel type and include $\mathrm{NO}_{x}$ as emissions of $\mathrm{NO}_{2}$. Final global gridded $\left(0.5^{\circ} \times 0.5^{\circ}\right)$ emissions for each compound, sector, and fuel group have been converted to emission fluxes $\left(\mathrm{kg} \mathrm{m}^{-2} \mathrm{~s}^{-2}\right)$, distributed over 12 months, and represent $\mathrm{NO}_{x}$ as $\mathrm{NO}$ to facilitate use in earth system models. Total NMVOCs in gridded products are additionally separated into 25 sub-VOC classes. Using a combination of updated energy consumption data and scaling procedures, $\mathrm{CEDS}_{\mathrm{GBD}-\mathrm{MAPS}}$ provides the most contemporary bottom-up global emission inventory to date and is the first inventory to report global emissions of multiple atmospheric pollutants from multiple fuel groups and sectors using consistent methodology. The following results section presents an overview of the CEDS ${ }_{\mathrm{GBD}-\mathrm{MAPS}}$ emission inven- 

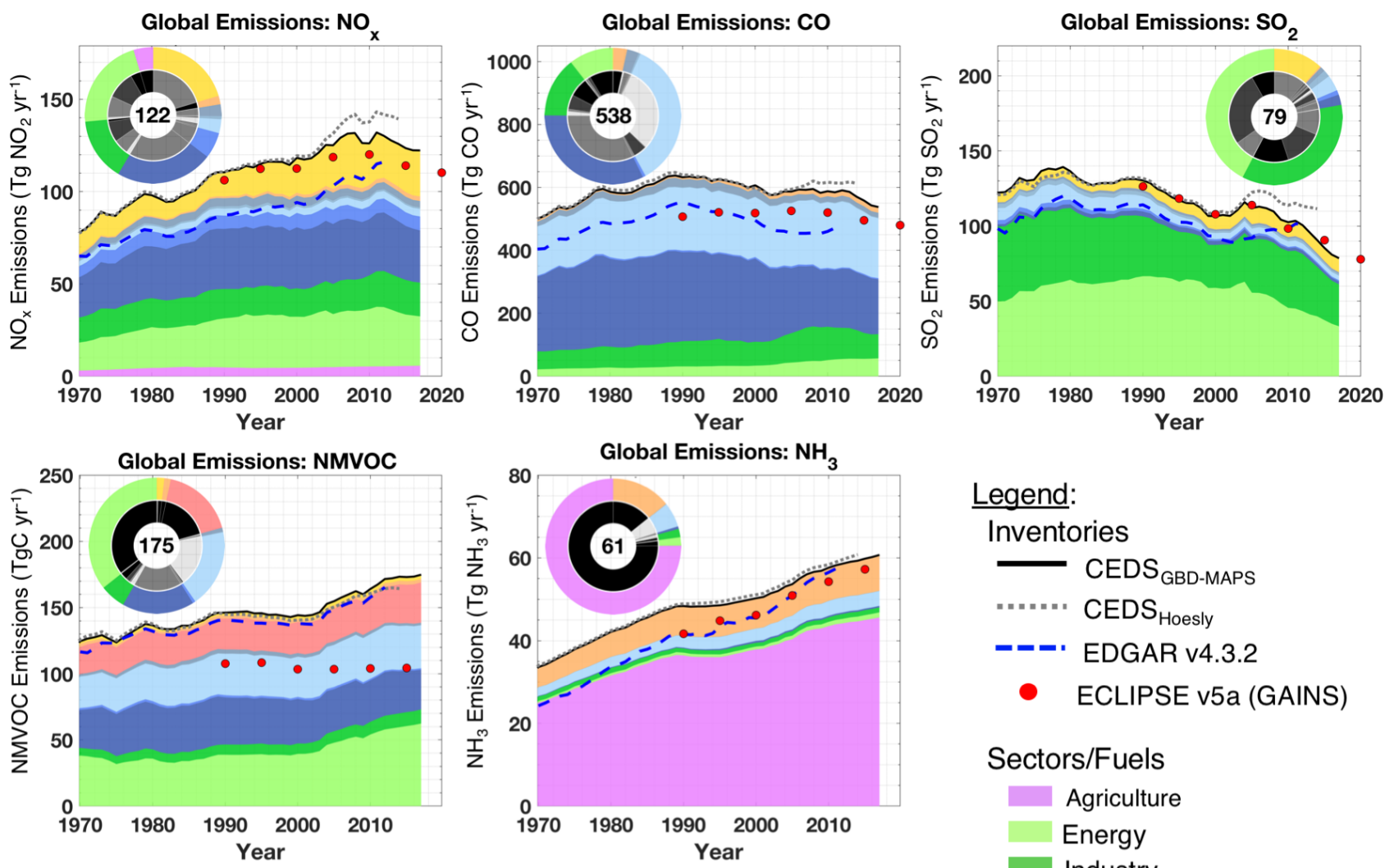

\section{Legend:}

Inventories

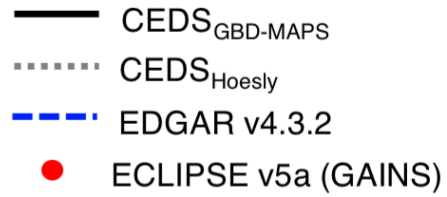

\section{Sectors/Fuels}

\section{Agriculture \\ Energy \\ Industry}

Global Emissions: OC
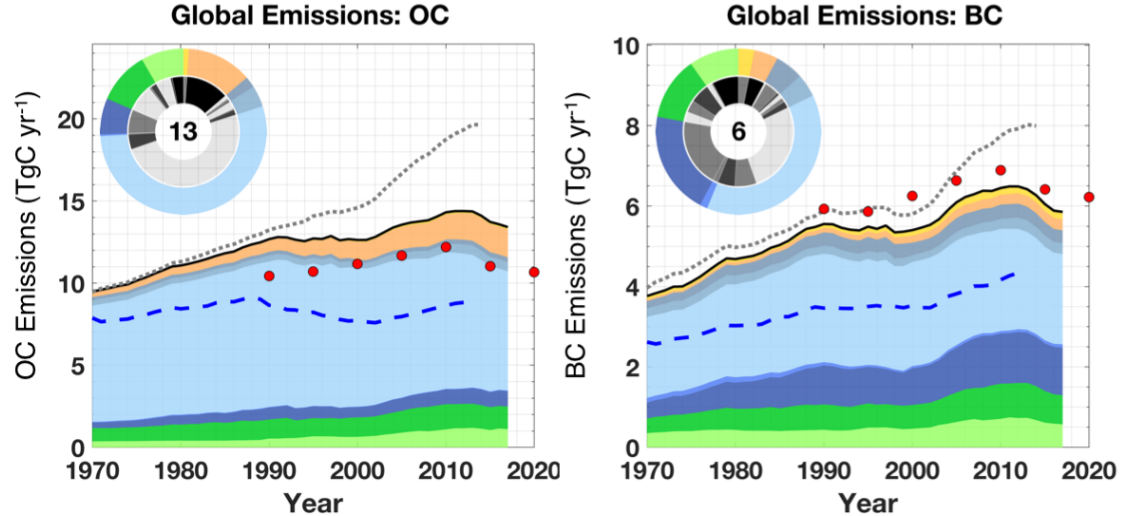

Road Transportation

Non-Road Trans.

Residential

Commercial

RCO-Other

Solvents

Waste

International Shipping

- Process Coal

Oil + Gas Biofuel

Figure 6. Time series of global annual emissions of $\mathrm{NO}_{x}$ (as $\left.\mathrm{NO}_{2}\right), \mathrm{CO}, \mathrm{SO}_{2}, \mathrm{NMVOCs} \mathrm{NH}_{3}, \mathrm{BC}$, and OC for all sectors and fuel types. Solid black lines are the $\mathrm{CEDS}_{\mathrm{GBD} \text {-MAPS }}$ inventory, with fractional sector contributions indicated by colors. Dashed gray lines are the

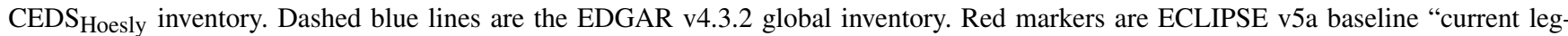
islation" (CLE) emissions (from the GAINS model) with data in 2015 and 2020 from GAINS CLE projections. All inventories include international shipping but exclude aircraft emissions. Pie chart inserts show fractional contributions of emission sectors to total 2017 emissions (outer) and fuel type contributions to each sector (inner). Emission totals for 2017 (units: $\mathrm{Tg} \mathrm{yr}^{-1}$; $\mathrm{Tg} \mathrm{C} \mathrm{yr}^{-1}$ for NMVOCs, OC, BC) are given inside each pie chart.

tory, with particular focus on emissions in 2017 and historical trends as a function of compound, sector, fuel type, and world region. Section 4 compares these results to other global emission inventories and discusses the magnitudes and sources of inventory uncertainties. Known issues in the inventory data at the time of submission are detailed in Sect. S4.

\subsection{Global annual total emissions in 2017}

Figures 6 and 7 show time series from 1970-2017 of global annual CEDS $\mathrm{GBD}_{\mathrm{GB}} \mathrm{MAPS}$ emissions for each emitted compound. Global CEDS $\mathrm{GBD}_{\mathrm{BAPS}}$ emissions for reactive gases in 2017 are $122 \mathrm{Tg}$ for $\mathrm{NO}_{x}\left(\right.$ as $\left.\mathrm{NO}_{2}\right), 538 \mathrm{Tg}$ for $\mathrm{CO}, 79 \mathrm{Tg}$ for $\mathrm{SO}_{2}, 175 \mathrm{TgC}$ for total NMVOCs, and $61 \mathrm{Tg}$ for $\mathrm{NH}_{3}$. Global 2017 emissions of carbonaceous aerosol are 13 and 
$6 \mathrm{Tg}$ C for OC and BC, respectively. The time series in Figs. 6 and 7 additionally show the contributions to global emissions from each of the 11 source sectors (Fig. 6) and four fuel groups (Fig. 7). Each panel in Fig. 6 additionally shows a pie chart with the fractional contribution of each sector to total global emissions in 2017 (outside), while the inner pie chart shows the fractional contributions from each of the fuel groups to each source sector. Numerical values for these fractional contributions are in Table S8. Global totals for 2017 are provided in the center of each pie chart. Global emissions from each compound are additionally split into contributions from 11 world regions (defined in Table S9) in Fig. 8 to aid in the interpretation of global trends below.

For global 2017 emissions of $\mathrm{NO}_{x}$, Fig. 6 and Table S8 show that $60 \%$ of $\mathrm{NO}_{x}$ emissions are associated with the energy generation (22\%), industry (15\%), and on-road transportation $(23 \%)$ sectors. These sectors have the largest contributions from emissions from coal combustion (> $46 \%$ for the energy and industry emissions) and the combined combustion of liquid fuels (oil) and natural gas (with these two fuels accounting for $100 \%$ of $\mathrm{NO}_{x}$ on-road emissions). Time series of regional contributions to global emissions in Fig. 8 additionally show that $50 \%$ of global $2017 \mathrm{NO}_{x}$ emissions are from the combined Other Asia/Pacific region (Table S9) (13 Tg), China (24 Tg), and international shipping (25 Tg). For global 2017 emissions of remaining gas-phase pollutants, $67 \%$ of $\mathrm{CO}$ emissions are from the on-road (100\%: oil + gas) and residential ( $86 \%$ : biofuel) sectors; $78 \%$ of $\mathrm{SO}_{2}$ emissions are from the energy generation (63\%: coal) and industry ( $38 \%$ coal, $36 \%$ process, $25 \%$ oil + gas) sectors; $89 \%$ of $\mathrm{NH}_{3}$ emissions are from the agriculture (100\%: process) and waste (100\%: process) sectors; and emissions of NMVOCs have the largest single contribution (36\%) from the energy sector, $99 \%$ of which are associated

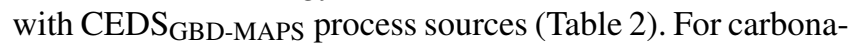
ceous aerosol in 2017, $58 \%$ of global BC emissions are from the residential (70\%: biofuel) and on-road (100\%: oil + gas) sectors, while $67 \%$ of global OC emissions are from the residential (92\%: biofuel) and waste (100\%: process) sectors. Figure 8 shows that in 2017, China is the dominant source of global $\mathrm{CO}\left(144 \mathrm{Tg}, 27 \%\right.$ of global total), $\mathrm{SO}_{2}(12 \mathrm{Tg}$, $15 \%$ of global total), $\mathrm{NH}_{3}$ (12 Tg, $20 \%$ of global total), OC (2.7 Tg C, $20 \%$ of global total), and BC (1.4 Tg C, $24 \%$ of global total). In contrast, Africa is the dominant source of global NMVOCs in 2017 (48 Tg C, $27 \%$ of global total), and international shipping is the dominant source of global $\mathrm{NO}_{x}$ emissions ( $25 \mathrm{Tg}, 20 \%$ of global total).

As discussed above in Sect. 2 and below in Sect. 4.2.4, the distinction between CEDS combustion- and process-level source categories for all species may result in the underrepresentation of emissions from combustion sources relative to those from CEDS process-level sectors. As shown in Table 2, for example, some combustion emissions from the energy, industry, and waste sectors, such as fossil fuel fires and waste incineration, are categorized as CEDS "process-level" source categories (Table 2). These emissions are allocated to the final CEDS process category rather than the CEDS total coal, biofuel, or oil and gas categories.

\subsection{Historical trends in annual global emissions}

Historical emission trends between 1970 and 2017 in Figs. 6 and 7 indicate that global emissions of each compound generally follow three patterns: (1) global $\mathrm{CO}$ and $\mathrm{SO}_{2}$ emissions peak prior to 1990 and generally decrease until 2017; (2) global emissions of $\mathrm{NO}_{x}, \mathrm{BC}$, and $\mathrm{OC}$ peak much later, around 2010, and then decrease until 2017; and (3) global emissions of $\mathrm{NH}_{3}$ and NMVOCs continuously increase throughout the entire time period. These trends generally reflect the sector-specific regulations implemented in dominant source regions around the world. For example, global emissions of $\mathrm{CO}$ generally decrease after the incorporation of catalytic converters in North America and Europe around 1990 (Figs. S7 and S8). Despite, however, continued reductions in these regions, global emissions of $\mathrm{CO}$ slightly increase between 2002 and 2012 due to simultaneous increases among the energy, industry, and residential sectors in China, India, Africa, and the Other Asia/Pacific region (Figs. S9-S12). Global CO emissions then decrease by $9 \%$ between 2012 and 2017, largely due to reductions in industrial coal, residential biofuel, and process energy sector emissions in China (Figs. S9, S17-S18, S20), associated with the implementation of emission control strategies (reviewed in Zheng et al., 2018) as well as continued reductions in on-road transport emissions in North America and Europe (Figs. S7S8). Similarly, global $\mathrm{SO}_{2}$ emissions decrease after peaking in 1979, largely due to emission control policies in the energy and industry sectors in North America and Europe (Figs. S7S8). While simultaneous increases in emissions from coal use in the energy and industry sectors in China result in a brief increase in global $\mathrm{SO}_{2}$ emissions between 1999 and 2004 (Figs. 6, S9), global $\mathrm{SO}_{2}$ emissions decline by $32 \%$ between 2004 and 2017 due to the implementation of stricter emission standards for the energy and industry sectors after 2010 in China (Zheng et al., 2018) as well as continued reductions in North America and Europe (Figs. S7-S8). Regional $\mathrm{SO}_{2}$ emission trends are particularly large with a factor of 9.5 decrease in total $\mathrm{SO}_{2}$ emissions in North America between 1973 and 2017, a factor of 6.9 decrease in Europe between 1979 and 2017, and a factor of 5.9 increase in China between 1970 and 2004, followed by a factor of 2.6 decrease after 2011 (Fig. 8). While China is the largest global contributor to $\mathrm{SO}_{2}$ emissions between 1994 and 2017, these large regional reductions, coupled with increasing $\mathrm{SO}_{2}$ emissions in the Other Asia/Pacific region, African countries, and India (Fig. 8), indicate that future global $\mathrm{SO}_{2}$ emissions will increasingly reflect activities in these other rapidly growing regions.

In contrast to historical emissions of $\mathrm{SO}_{2}$ and $\mathrm{CO}$, global emissions of $\mathrm{NO}_{x}, \mathrm{BC}$, and $\mathrm{OC}$ peak later, between 2011 

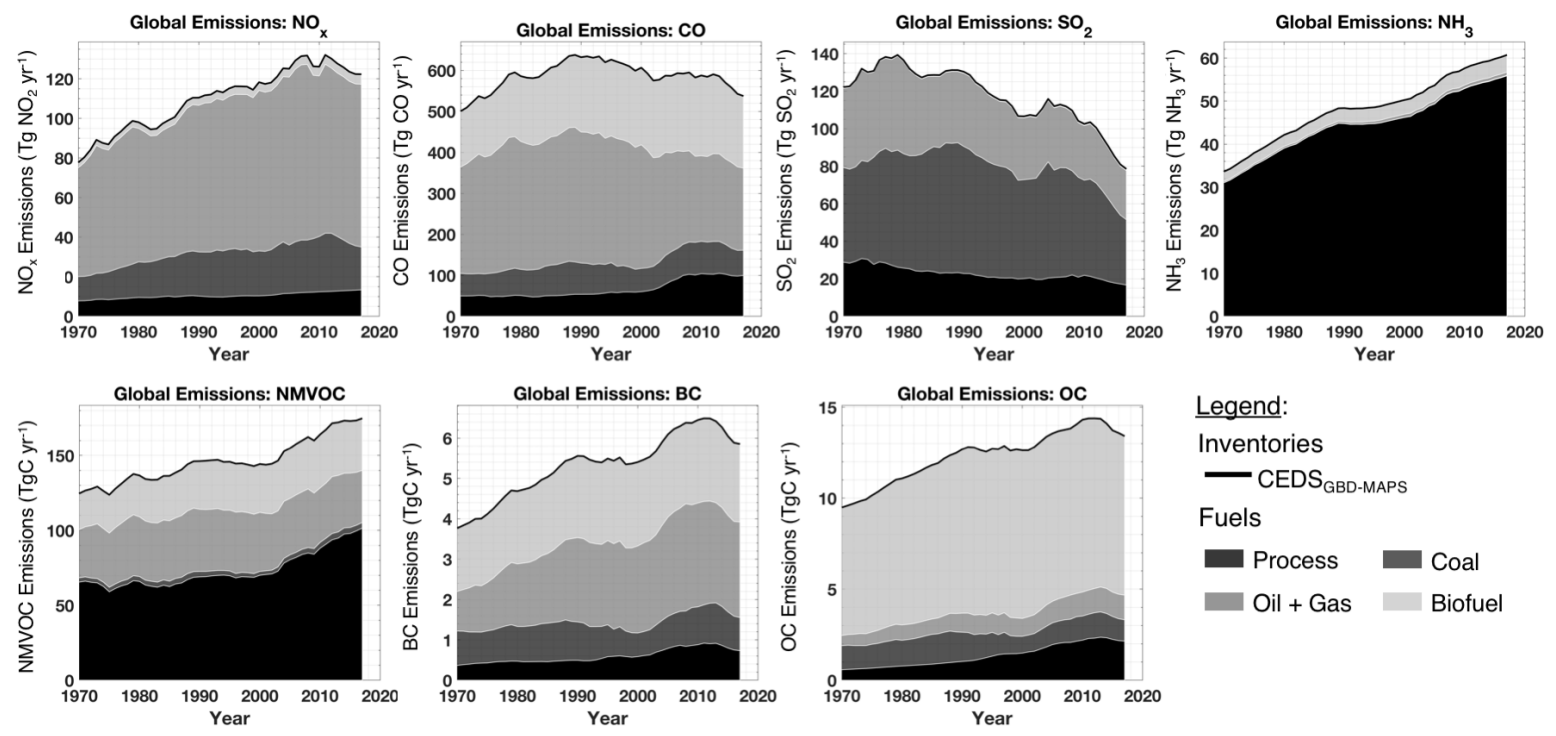

Legend:

Inventories

CEDS $_{\text {GBD-MAPS }}$

Fuels

Process Coal

Oil + Gas Biofuel

Figure 7. Time series of global annual emissions of $\mathrm{NO}_{x}, \mathrm{CO}, \mathrm{SO}_{2}, \mathrm{NH}_{3}, \mathrm{NMVOCs}, \mathrm{BC}$, and $\mathrm{OC}$ for all sectors, colored by fuel group.
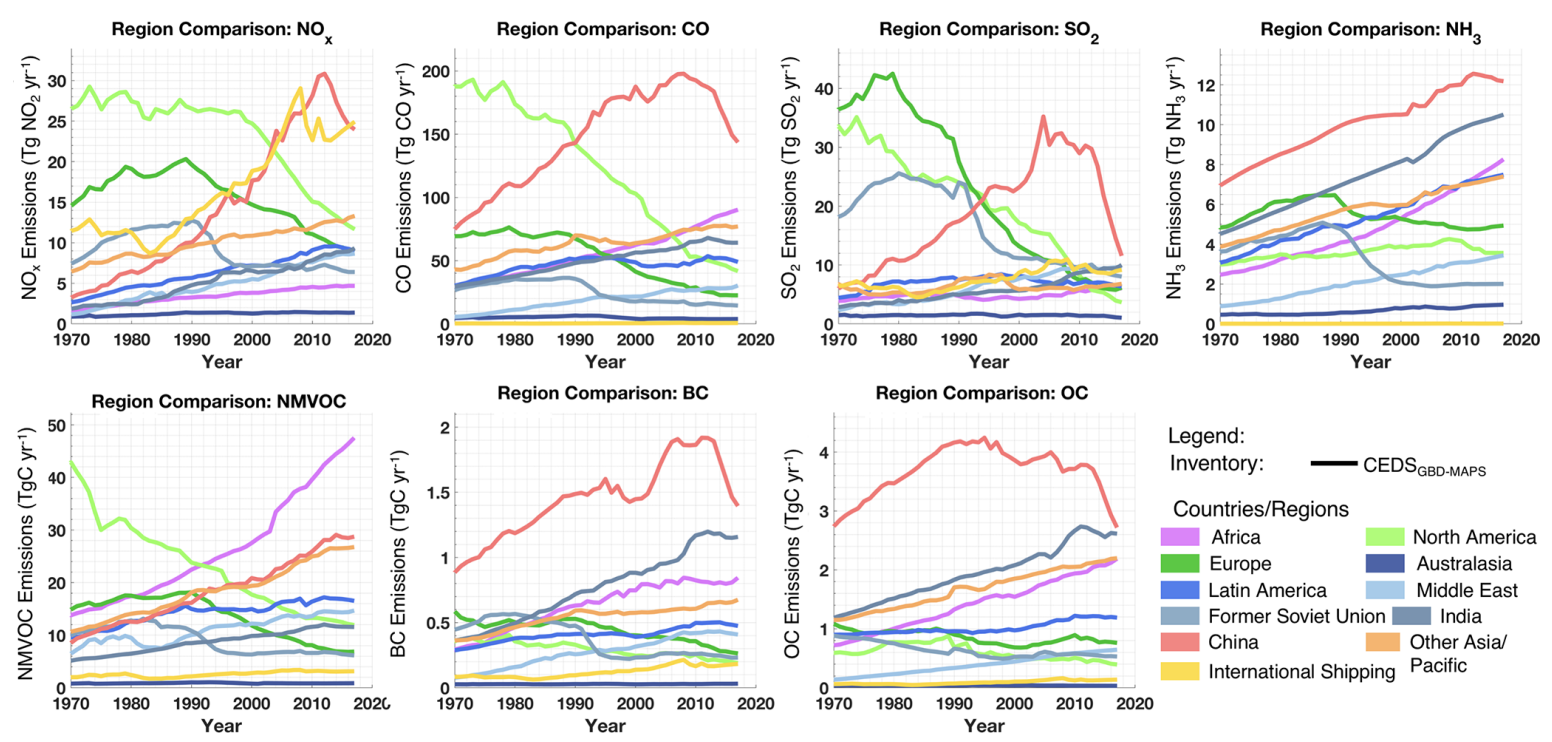

Figure 8. Time series of global annual CEDS $\mathrm{GBD}$-MAPS emissions of $\mathrm{NO}_{x}, \mathrm{CO}, \mathrm{SO}_{2}, \mathrm{NH}_{3}, \mathrm{NMVOCs}$, BC, and OC for all sectors and fuel types, split into 11 regions and countries (defined in Table S9).

and 2013. Global emissions then decrease by $7 \%, 9 \%$, and $7 \%$, respectively, by 2017 (Fig. 6). These trends also reflect the sector-specific regulations implemented in dominant source regions. For $\mathrm{NO}_{x}$ for example, global emissions between 1970 and 2017 are dominated by the combustion of coal, oil, and gas in the on-road transportation, energy generation, industry, and international shipping sectors (Figs. 6, 8). Global on-road transportation emissions are generally flat between 1988 and 2013 due to competing trends across world regions. While more stringent vehicle emission standards result in more than a factor of 2 decrease in on-road transportation $\mathrm{NO}_{x}$ emissions in North America and Europe be- tween 1992 and 2017 (Figs. S7-S8), on-road transport emissions in China, India, and the Other Asia/Pacific region simultaneously experience between a factor of 1.3 and 2.8 increase (Figs. S9-S11). Subsequent reductions between 2013 and 2017 in global on-road emissions correspond to a $12 \%$ reduction in on-road transportation emissions in China due to the phase-in of stricter emission standards (Zheng et al., 2018), coupled with a continued decrease in emissions from North America and Europe. Global $\mathrm{NO}_{x}$ emissions from the energy and industry sectors increase by up to a factor of 6 between 1970 and 2011 due to regional increases in China, India, the Other Asia/Pacific region, and African countries, 
with reductions between 2011 and 2017, again largely from reductions in China from stricter emissions control policies for coal-fired power plants and coal use in industrial processes (Zheng et al., 2018; Liu et al., 2015). Global emissions of $\mathrm{NO}_{x}$ from waste combustion and agricultural activities also increased by $2 \%$ and $65 \%$, respectively, between 1970 and 2017 , also contributing to the offset of recent reductions in emissions from regulated combustion sources (Fig. 6). Similar to global $\mathrm{NO}_{x}$ emissions, trends in historical BC and OC emissions reflect a balance between emission trends in North America, Europe, and other world regions, with reduction between 2010 and 2017 largely driven by reductions in emissions from China (Figs. 8, S9). In contrast to $\mathrm{NO}_{x}$ emissions, however, $\mathrm{BC}$ and $\mathrm{OC}$ emissions are dominated by contributions from biofuel combustion in the residential sector as well as on-road transportation, industry, and energy sectors for $\mathrm{BC}$ and the waste sector for global OC (Fig. 6). Though emissions of $\mathrm{BC}$ and $\mathrm{OC}$ have a higher level of uncertainty relative to other compounds (Sect. 4), emissions from African countries and the Other Asia/Pacific region experience growth in $\mathrm{BC}$ and $\mathrm{OC}$ emissions from these sectors. The exceptions are in China and India, both of which experience a plateau or reduction in $\mathrm{BC}$ and $\mathrm{OC}$ emissions from the residential, energy (China only), industry, and onroad transportation sectors between 2010 and 2017. In India, reductions in $\mathrm{BC}$ and $\mathrm{OC}$ emissions from the residential and informal industry sectors are expected to continue under policies to switch to cleaner residential fuels and energy sources, while $\mathrm{BC}$ emissions from on-road transport may increase due to increased transport demand (Venkataraman et al., 2018). Similar to trends in $\mathrm{SO}_{2}$ emissions, increasing trends in total $\mathrm{OC}$ and $\mathrm{BC}$ emissions from Africa, India, Latin America, the Middle East, and the Other Asia/Pacific region, coupled with large decreases in emissions from China, North America, and Europe (Fig. 8), indicate that global emissions will increasingly reflect activities in these rapidly growing regions.

Trends in historical emissions of NMVOCs and $\mathrm{NH}_{3}$ differ from other pollutants in that they continuously increase between 1970 and 2017. Global emissions of $\mathrm{NH}_{3}$ increase by $81 \%$ between 1970 and 2017 and are largely associated with emissions from agricultural practices $(75 \%$ in 2017) and waste disposal and handling (14\% in 2017) (Fig. 6, Table S8). Unlike emissions from combustion sources, there are no large-scale regulations outside of Europe targeting $\mathrm{NH}_{3}$ emissions from agricultural activities, such as livestock manure management. As a result, global agricultural emissions of $\mathrm{NH}_{3}$ increase between 1970 and 2017 by $82 \%$, driven by increases in all regions other than Europe (Figs. 6, S6-S12). Similarly, global $\mathrm{NH}_{3}$ emissions from the waste sector increase by $77 \%$ between 1970 and 2017, driven by increases in Latin America, the Other Asia/Pacific region, Africa, and India (Figs. S10-S12). Global emissions of NMVOCs increase by $40 \%$ between 1970 and 2017 and are largely associated with emissions from the on-road transport, residential, energy, industry, and solvent use sectors (Fig. 6).
In contrast to other emitted pollutants, Africa is the largest global source of NMVOC emissions between 2010 and 2017, largely due to large contributions and continued increases in emissions from the residential (factor of 2.7) and energy (factor of 4) sectors (Fig. S12). Increases in energy sector emissions after 2003 are largely driven by increases in fugitive emissions from select African countries, including Nigeria, Kenya, Angola, and Mozambique. Emissions from China are the second-largest global NMVOC source between 1996 and 2017 (Fig. 8), while the Other Asia/Pacific region is the thirdlargest source between 1999 and 2017. Total NMVOCs in China increase by a factor of 3.4 between 1970 and 2017 due to activity increases in the solvent, energy, and industry sectors (Zheng et al., 2018), while targeted emission controls for the residential and on-road transport sectors result in their reduced contributions to NMVOC emissions between 2012 and 2017 (Fig. S9). Total emissions of NMVOCs in Europe and North America decrease by up to a factor of 2.4 between 1970 and 2017 due to reductions in all source sectors, except for energy emissions in North America, which increase between 2007 and 2011 and remain flat through 2017 (Fig. S7).

To provide a fuel-centric perspective of global historical emissions trends, Fig. 7 illustrates the contributions from the combustion of coal, solid biofuel, the sum of liquid fuel and natural gas, and all remaining CEDS "process-level" sources (Table 2) to total global emissions between 1970 and 2017. Reductions discussed above between 2010 and 2017 for global emissions of $\mathrm{NO}_{x}, \mathrm{CO}, \mathrm{SO}_{2}, \mathrm{BC}$, and $\mathrm{OC}$ are largely associated with reductions in coal combustion from the energy, industry, and residential sectors associated with emission control policies and residential fuel replacement in China as well as coal-fired power plant reductions in North America and Europe (Figs. 7, S13, S17-S18). Despite large reductions in emissions, China is still the single largest source of global emissions from coal combustion in 2017 ( $23 \%-64 \%$ for each compound except $\mathrm{NH}_{3}$ ). Figure $\mathrm{S} 17$, however, also shows that emissions from coal combustion are simultaneously increasing in India, the Other Asia/Pacific region, and Africa. Specifically, $\mathrm{SO}_{2}$ emissions from coal combustion in India are set to surpass those from China by 2018 if recent CEDS $_{\text {GBD-MAPS }}$ trends hold. For solid biofuel combustion, global emissions of all compounds are primarily associated with the residential sector (Fig. S14), with recent reductions in biofuel $\mathrm{CO}, \mathrm{SO}_{2}, \mathrm{BC}$, and $\mathrm{OC}$ emissions largely from reductions in China (Fig. S18). In contrast, biofuel emissions from all other regions remain relatively flat or increase between 1970 and 2017, though biofuel emissions of NMVOCs, $\mathrm{CO}, \mathrm{SO}_{2}$, and $\mathrm{OC}$ in India as well as $\mathrm{SO}_{2}$ emissions in North America both decrease between 2010 and 2017 (Fig. S18). In 2017, biofuel emissions of all compounds are dominated by emissions from either Africa ( $\left.\mathrm{NO}_{x}, \mathrm{SO}_{2}, \mathrm{NH}_{3}, \mathrm{NMVOC}, \mathrm{BC}\right)$ or India (OC). For oil and gas combustion, global emissions of all compounds are primarily associated with on-road transportation, international shipping, and energy and industry $\left(\mathrm{SO}_{2}\right.$ only) sec- 
tors, with general decreases in associated emissions in North America and Europe between 1970 and 2017 and increases in other regions (Fig. S19). In contrast to other combustion sectors and fuels, emissions of $\mathrm{NO}_{x}, \mathrm{CO}$, NMVOCs, $\mathrm{BC}$, and $\mathrm{OC}$ from the combustion of liquid fuels and natural gas in China remain relatively flat or slightly decrease between 2010 and 2017. Dominant global regions vary by compound (Fig. S19) and include international shipping $\left(\mathrm{NO}_{x}\right.$, $\mathrm{SO}_{2}$ ), Africa (OC), India (BC), North America $\left(\mathrm{CO}, \mathrm{NH}_{3}\right)$, and the Other Asia/Pacific region (NMVOCs). Global CEDS process source emissions, which include contributions from some fuel combustion processes (Table 2), decrease between 2010 and 2017 for $\mathrm{CO}, \mathrm{SO}_{2}, \mathrm{BC}$, and OC. These trends are primarily associated with reductions in emissions from the energy and industry sectors. In contrast, process source contributions to $\mathrm{NO}_{x}, \mathrm{NH}_{3}$, and NMVOCs increase over this same time period due to increases in non-combustion agricultural and solvent use emissions as well as emissions from waste disposal and energy generation and transformation (Fig. S16). Increases in emissions from these sectors between 1970-2017 drive the continuous increases in global $\mathrm{NH}_{3}$ and NMVOCs, discussed above. Dominant source regions in 2017 of these process-level emissions include China $\left(\mathrm{NO}_{x}, \mathrm{CO}, \mathrm{NH}_{3}, \mathrm{BC}, \mathrm{OC}\right)$, India $\left(\mathrm{SO}_{2}\right)$, and African countries (NMVOCs) (Fig. S20).

\section{Discussion}

\subsection{Comparison to global inventories}

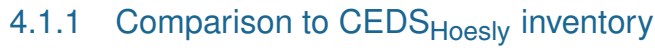

As a result of the similar methodologies, Fig. 6 shows that $\mathrm{CEDS}_{\mathrm{GBD}-\mathrm{MAPS}}$ and $\mathrm{CEDS}_{\text {Hoesly }}$ emission inventories predict similar magnitudes and historical trends in global emissions of each compound between 1970 and 2014. The two inventories, however, diverge in recent years due to the incorporation of updated activity data and both updated and new scaling emission inventories included in the CEDS $\mathrm{GBD}_{\mathrm{GAPS}}$ system. For global emissions of $\mathrm{NO}_{x}, \mathrm{CO}$, and $\mathrm{SO}_{2}$, the $\mathrm{CEDS}_{\mathrm{GBD}-\mathrm{MAPS}}$ emissions are smaller than the $\mathrm{CEDS}_{\text {Hoesly }}$ emissions after 2006 and show a faster decreasing trend. By 2014, global emissions of these compounds are between $7 \%$ and $21 \%$ lower than previous $\mathrm{CEDS}_{\text {Hoesly }}$ estimates. These differences are largely associated with large emission reductions in China as a result of the updated national-level scaling inventory from Zheng et al. (2018), along with the added DICE-Africa (Marais and Wiedinmyer, 2016) and SMoGIndia (Venkataraman et al., 2018) scaling inventories. Differences in emissions from India and Africa in the two CEDS inventories are discussed in Sect. 2 (Fig. 3) and, combined, account for $\sim 60 \%$ of the reduction in global $\mathrm{NO}_{x}$ emissions, $23 \%$ of the reduction in global CO, and $14 \%$ of the reduction in global $\mathrm{SO}_{2}$. The largest differences between these two inventories in India and Africa are the reduced $\mathrm{NO}_{x}$ emissions from the transport sector as well as reduced energy emissions of $\mathrm{SO}_{2}$ in India. Remaining differences between $\mathrm{NO}_{x}$ and $\mathrm{SO}_{2}$ emissions in the two CEDS inventories are largely associated with the updated China emission inventory from Zheng et al. (2018), which reports lower emissions in 2010 and 2012 than a previous version of the MEIC inventory that was used to scale China emissions in the CEDS $S_{\text {Hoesly }}$ inventory (C. Li et al., 2017). These emission reductions are largely associated with the industrial and residential sectors in China and are partially offset by a simultaneous increase in transportation emissions of all compounds relative to $\mathrm{CEDS}_{\text {Hoesly }}$.

For global emissions of $\mathrm{NH}_{3}$ and NMVOCs, these species remain relatively unchanged between the $\mathrm{CEDS}_{\text {Hoesly }}$ and $\mathrm{CEDS}_{\mathrm{GBD}-\mathrm{MAPS}}$ inventories. In $2014 \mathrm{CEDS}_{\mathrm{GBD}-\mathrm{MAPS}}$ emissions are $5 \%$ higher than $\mathrm{CEDS}_{\text {Hoesly }}$ emissions for

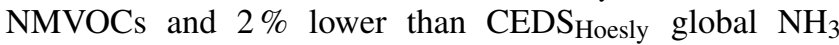
emissions. Emissions of $\mathrm{NH}_{3}$ remain relatively unchanged (within $<2 \%$ ) from dominant source regions, including India, Africa (Fig. 3), and China. In contrast, emissions of NMVOCs from Africa and China in the DICE-Africa and Zheng et al. (2018) scaling inventories are larger than those

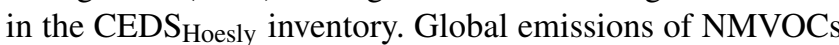
are also higher in the EDGAR v4.3.2 inventory relative to the previous version used in the $\mathrm{CEDS}_{\text {Hoesly inventory. }}$ NMVOCs are particularly large from the process energy sector emissions in Africa (Fig. S12), which primarily include fugitive emissions from oil and gas operations (Table 2). Default energy sector emissions from "non-combustion" processes are taken from the EDGAR inventory and are not scaled to the DICE-Africa inventory. Therefore, the large increase in these emissions in Africa relative to $\mathrm{CEDS}_{\text {Hoesly }}$ is largely driven by changes in the EDGAR v4.3.2 inventory, with emissions from the 1B2_Fugitive_Fossil fuels sector increasing for example by a factor of 5 in Nigeria between 2003 and 2017.

Global emissions of $\mathrm{OC}$ and $\mathrm{BC}$ have the largest differences between the two CEDS inventories, with CEDS $_{\text {GBD-MAPS }}$ emissions consistently smaller than

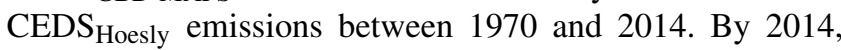
$\mathrm{CEDS}_{\mathrm{GBD}-\mathrm{MAPS}}$ emissions of $\mathrm{BC}$ and $\mathrm{OC}$ are $24 \%$ and $33 \%$ smaller than corresponding $\mathrm{CEDS}_{\text {Hoesly }}$ emissions. In the $\mathrm{CEDS}_{\text {Hoesly }}$ inventory, default emissions of $\mathrm{BC}$ and $\mathrm{OC}$ are not scaled, and therefore these differences are largely associated with the added scaling inventories, discussed in Sect. 2 and shown in Table 3. As shown in Figs. S3-S4, the added scaling of $\mathrm{BC}$ and $\mathrm{OC}$ emissions leads to a reduction in global $\mathrm{CEDS}_{\mathrm{GBD}-\mathrm{MAPS}}$ emissions of $\mathrm{OC}$ in all scaled regions and a reduction in $\mathrm{BC}$ emissions in all regions other than India. In India, increases in industry and residential BC emissions from the SMoG-India scaling inventory result in a slight increase in $\mathrm{BC}$ emissions relative to the $\mathrm{CEDS}_{\mathrm{Hoesly}}$ inventory (Fig. 3). Waste emissions of OC and $\mathrm{BC}$ are also reduced in the $\mathrm{CEDS}_{\mathrm{GBD} \text {-MAPS }}$ inventory due to updated assumptions for the fraction of waste burned (Sect. S1.1). 
As discussed in Hoesly et al. (2018) and further below, BC and $\mathrm{OC}$ emissions typically have the largest uncertainties of all the emitted species, and their recent changes in the residential and waste sectors are particularly uncertain.

The relative contributions of each source sector to emissions in the two CEDS versions are additionally shown in Fig. S21. This comparison shows that the fractional sectoral contributions to global emissions in 2014 are the same to within $10 \%$ in the two CEDS inventories. The largest differences are a $9 \%$ increase in the relative contribution of on-road transportation emissions of $\mathrm{CO}$ and reductions in the relative contribution of waste emissions across all compounds. These trends reflect the large update to default waste emissions described above as well as changes associated with the DICE-Africa and national China scaling inventories.

Similar to the total global emissions, changes between the two CEDS versions for the national-level and $0.5^{\circ} \times 0.5^{\circ}$ gridded products will also result from updates to the energy consumption data, scaling inventories (Sects. 2.2-2.3), and spatial distribution proxies from EDGAR v4.3.2 (Sect. 2.1). Time series of differences between the CEDS ${ }_{\text {Hoesly }}$ and CEDS $_{\text {GBD-MAPS }}$ inventories for 11 world regions are shown for each compound in Fig. S22. Fig. S22 shows that CEDS $_{\text {GBD-MAPS }}$ emissions are, in recent years, generally lower in each region, with the greatest differences in Africa, India, and China. The relative changes in Africa and India are discussed in Sect. 2. For China, the CEDS ${ }_{\text {GBD-MAPS }}$ emissions are generally lower than the $\mathrm{CEDS}_{\text {Hoesly }}$ estimates after the year 2010 as a result of the updated scaling inventory. Regional differences between inventories are also greater for $\mathrm{OC}$ and $\mathrm{BC}$ emissions relative to other compounds due to the added scaling procedure discussed in Sect. 2. Differences in spatial distributions are not discussed here as changes represent differences in the spatial proxies, which are largely from updates to the EDGAR inventory.

\subsubsection{Comparison to other global inventories (EDGAR and GAINS)}

Figure 6 additionally provides a comparison of the CEDS $_{\text {GBD-MAPS }}$ global emissions to those from two widely used inventories: EDGAR v4.3.2 (Crippa et al., 2018; ECJRC, 2018) and ECLIPSE v5a (GAINS) (IIASA, 2015; Klimont et al., 2017). For a comparison of global emissions across similar emission sectors, the EDGAR v4.3.2 inventory in Fig. 6 includes emissions from all reported sectors (including international shipping), except for those from agricultural waste burning and domestic and international aviation. Similarly, the GAINS ECLIPSE v5a baseline scenario inventory in Fig. 6 includes all reported emissions other than those from agricultural waste burning. These include contributions from aggregate residential and commercial combustion sources ("dom"), energy generation ("ene"), industrial combustion processes ("ind"), road and non-road transportation ("tra"), agricultural practices ("agr"), and waste disposal (“wst”). GAINS ECLIPSE v5a baseline estimates for international shipping emissions are also included in Fig. 6. A table with sectoral mappings of the CEDS $_{\text {GBD-MAPS }}$, EDGAR v4.3.2, and GAINS inventories is provided in Table S10.

The comparison in Fig. 6 shows that global emissions of

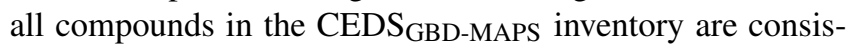
tently larger than in the EDGAR v4.3.2 inventory (Crippa et al., 2018). Global CEDS $\mathrm{GBD}$-MAPS emissions of $\mathrm{NO}_{x}, \mathrm{SO}_{2}$, $\mathrm{CO}$, and NMVOCs are at least $27 \%$ larger, while global emissions of $\mathrm{NH}_{3}, \mathrm{BC}$, and $\mathrm{OC}$ are within $52 \%$. Figure $\mathrm{S} 23$ indicates that differences in global $\mathrm{BC}$ and $\mathrm{OC}$ emissions are largely due to higher waste and residential and commercial emissions in the CEDS ${ }_{\text {GBD-MAPS }}$ inventory. Figure 6, however, also shows that the trends in global emissions are similar between EDGAR v4.3.2 and CEDS ${ }_{\text {GBD-MAPS }}$ for most compounds. For example, between 1970 and 2012, global emissions of $\mathrm{SO}_{2}, \mathrm{NH}_{3}, \mathrm{NMVOCs}$, and $\mathrm{BC}$ peak in the same years. Global $\mathrm{CO}$ and $\mathrm{NO}_{x}$ emissions both peak 1 year earlier in the CEDS $\mathrm{GBD}_{\mathrm{GB}-\mathrm{MAPS}}$ inventory but otherwise follow similar historical trends. Trends in OC emissions are the most different between the two inventories, with a peak in emissions in 1988 in the EDGAR inventory compared to 2012 in the CEDS $\mathrm{GBD}_{\mathrm{GB} \text { MAPS }}$ inventory. A comparison of relative sectoral contributions in Fig. S23 shows that these differences in OC emissions are largely due to the residential and commercial sectors, which may be underestimated in the EDGAR v4.3.2 inventory relative to GAINS (Crippa et

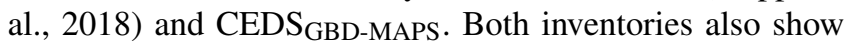
a net increase in global emissions of all compounds other than $\mathrm{SO}_{2}$ between 1970 and 2012. Global $\mathrm{SO}_{2}$ emissions follow a similar trend until 2007, after which the emissions in CEDS $_{\text {GBD-MAPS }}$ decrease at a faster rate than in EDGAR v4.3.2. These differences are largely due to the energy sector, which increases between 2006 and 2012 in EDGAR and decreases as a result of emission reductions in China

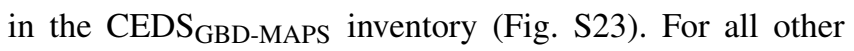
compounds, the rate of increase in emissions between 1970 and 2012 is also slightly different between the two inventories. For example, $\mathrm{NH}_{3}$ emissions in the $\mathrm{CEDS}_{\mathrm{GBD}-\mathrm{MAPS}}$ inventory increase by $74 \%$ compared to a $139 \%$ increase in EDGAR. In contrast, $\mathrm{BC}$ and $\mathrm{OC}$ emissions increase at a faster rate in the CEDS ${ }_{\text {GBD-MAPS }}$ inventory. Due to similar sources of uncertainty and the additional scaling of CEDS $_{\text {GBD-MAPS }}$ emissions to EDGAR (except for BC and OC), levels of uncertainty between the two inventories are expected to be similar, as discussed further in Sect. 4.2.

Similar to the comparison with EDGAR emissions, Fig. 6 also shows that global emissions in the $\mathrm{CEDS}_{\mathrm{GBD}-\mathrm{MAPS}}$ inventory are generally larger than emission estimates from the GAINS model, published as part of the ECLIPSE v5a inventory (referred to here as GAINS) (Klimont et al., 2017). Two exceptions are for $\mathrm{SO}_{2}$ emissions, which are up to $6 \%$ lower than GAINS in select years, and BC emissions, which are consistently $5 \%-15 \%$ lower than GAINS for all years. While the sectoral definitions may slightly differ between 
these inventories, Fig. S24 shows that these differences are largely due to different trends in energy and industry $\mathrm{SO}_{2}$ emissions between 2005 and 2015 and consistently lower $\mathrm{BC}$ emissions from the residential and commercial sector

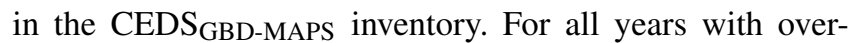
lapping data between 1990 and 2015, the absolute magnitude of global emissions is within $\pm 15 \%$ for $\mathrm{NO}_{x}, \mathrm{SO}_{2}$, $\mathrm{NH}_{3}$, and $\mathrm{BC}$; within $22 \%$ for $\mathrm{CO}$ and $\mathrm{OC}$; and within $50 \%$ for NMVOCs. Historical trends in each inventory are also similar for all compounds other than $\mathrm{CO}$ and NMVOCs (Fig. 6). Peak global emissions occur between 2010 and 2012 for $\mathrm{NO}_{x}, \mathrm{BC}$, and $\mathrm{OC}$, while both inventories show a net decrease in emissions in $\mathrm{SO}_{2}$ and a net increase in emissions of $\mathrm{NH}_{3}$. In contrast, GAINS emissions of $\mathrm{CO}$ peak in 2010, while CEDS $_{\text {GBD-MAPS }}$ emissions peak in 1990. The largest differences in historical trends are for global NMVOC emissions, with GAINS showing a $3 \%$ decrease between 1990 and 2010, while CEDS GBD-MAPS NMVOC emissions increase by $13 \%$ over this same time period (Fig. 6). Sectoral contributions between the two inventories in Fig. S24 indicate that these differences are largely due differences in the energy, industry, and on-road transport emissions of NMVOCs. Uncertainties in the GAINS model have been previously estimated to fall between $10 \%$ and $30 \%$ in Europe for gas-phase species (Schöpp et al., 2005) and within the uncertainty estimates for BC and OC of other global bottomup inventories (Klimont et al., 2017; Bond et al., 2004), as discussed in the following section.

\subsection{Uncertainties}

The level and sources of uncertainty in the $\mathrm{CEDS}_{\mathrm{GBD}-\mathrm{MAPS}}$ inventory are similar to those in the $\mathrm{CEDS}_{\text {Hoesly inventory, }}$ which are largely a function of uncertainty in the activity data, emission factors, and country-level inventories. As these uncertainties have been previously discussed in Hoesly et al. (2018), we have not performed a formal uncertainty analysis here but rather provide a brief summary of the sources of uncertainty associated with this work. We note plans for a robust uncertainty analysis in an upcoming release of the CEDS core system. While this section highlights many of the challenges associated with estimating comprehensive and accurate global bottom-up emission inventories, such inventories remain vital for their use in chemistry and climate models and for the development and evaluation of future control and mitigation strategies.

\subsubsection{Uncertainties in activity data}

As discussed in Sect. 2.1, CEDS default emissions from combustion sources are largely informed by fuel consumption data from the IEA 2019 World Energy Statistics Product (IEA, 2019). While this database provides energy consumption data as a function of detailed source sector and fuel type for most countries, the IEA data are uncertain and include breaks in time series data that can lead to abrupt changes in the $\mathrm{CEDS}_{\mathrm{GBD}-\mathrm{MAPS}}$ emissions for select sectors, fuels, and countries. For example, Fig. S7 shows an order of magnitude decrease $(0.1 \mathrm{TgC})$ in OC industrial emissions from North America between 1992 and 1993, which is driven by a break in IEA biofuel consumption data for the non-specified manufacturing industry sector (CEDS sector: 1A2g_Ind-Combother) in the United States. While the magnitude of this particular change is negligible on the global scale, this is not the case for all sectors. For example, as noted in Sect. S4, a known issue in the IEA data in China in the energy sector causes peaks in the associated $\mathrm{NO}_{x}$ and $\mathrm{SO}_{2} \mathrm{CEDS}_{\mathrm{GBD}-\mathrm{MAPS}}$ emissions in 2004. These peak emissions may be overestimated by up to 4 and $10 \mathrm{Tg}$, respectively, which is large enough to impact historical trends in both regional (Fig. 8: $\mathrm{NO}_{x}$ and $\mathrm{SO}_{2}$ ) and global (Figs. 6-7: $\mathrm{SO}_{2}$ ) emissions. These point to areas where improvements could be made to the underlying driver data in future work.

\subsubsection{Uncertainties in global bottom-up inventories}

Uncertainties in bottom-up emission inventories vary as a function of space, time, and compound, making total uncertainties difficult to quantify. Default emission estimates in the CEDS system are subject to uncertainties in underlying activity data, such as IEA energy consumption data, as well as activity drivers for process-level emissions. Knowledge of accurate emission factors also drives inventory uncertainty as EFs are not often available for all sectors in countries with emerging economies and are heavily dependent on the use, performance, and enforcement of control technologies within each sector and country (e.g., Zhang et al., 2009; Wang et al., 2015). While improvements in data collection and reporting standards may decrease the uncertainty in some underlying sources over time, the most recent years of CEDS ${ }_{\mathrm{GBD}-M A P S}$ emissions are still subject to considerable uncertainty. For instance, the degree of local and national compliance with control measures is often variable or unknown (e.g., Wang et al., 2015; Zheng et al., 2018); recent activity and regional emissions data are often updated as new information becomes available; and emissions in generally more uncertain regions, including India and Africa, are becoming an increasingly large fraction of global totals. Additionally, from a methodological standpoint, default CEDS emissions after 2010 also currently rely on the projection of emission factors from the GAINS EMF30 data release for sectors and countries where contemporary regional scaling inventories are not available.

As the CEDS system uses a "mosaic" approach and incorporates information from other global- and national-level inventories, the final $\mathrm{CEDS}_{\mathrm{GBD}-\mathrm{MAPS}}$ emissions will also be subject to the same sources and levels of uncertainty as these external inventories. For example, as discussed in Sect. 2.1, default process-level emissions in CEDS $_{\mathrm{GBD}-M A P S}$ are derived using emissions from the EDGAR v4.3.2 inventory, 
with many countries additionally scaled to this inventory during Step 2. As reported and discussed in Crippa et al. (2018), EDGAR v4.3.2 emissions for 2012 at the regional level are estimated to have the smallest uncertainties for $\mathrm{SO}_{2}$, between $14.4 \%$ and $47.6 \%$, with uncertainties in $\mathrm{NO}_{x}$ between $17.2 \%$ and $69.4 \%$ (up to $124 \%$ for Brazil), CO between $25.9 \%$ and $123 \%$ (lower for industrialized countries), and NMVOCs between $32.7 \%$ and $148 \%$ (lower for industrialized countries). Emissions of $\mathrm{NH}_{3}$ are highly uncertain in all inventories (186\% to $294 \%$ in EDGAR) due to uncertainties in the reporting of agricultural statistics and emission factors that will depend on individual farming practices, biological processes, and environmental conditions (e.g., Paulot et al., 2014). As noted in Crippa et al. (2018) and Klimont et al. (2017), EDGAR v4.3.2 and GAINS uncertainty estimates for $\mathrm{BC}$ and $\mathrm{OC}$ fall within the factor of 2 range that has been previously estimated by the seminal work of Bond et al. (2004). While $\mathrm{CEDS}_{\mathrm{GBD}-\mathrm{MAPS}}$ emissions are not scaled to EDGAR v4.3.2 BC and OC emissions, estimates are derived from similar sources and are therefore expected to be consistent with uncertainties in both EDGAR and other global bottom-up inventories. It should also be noted that these reported uncertainty estimates from EDGAR only reflect the uncertainties associated with the emission estimation process and do not account for the potential of missing emissions sources or super-emitters within a given sector (Crippa et al., 2018).

To evaluate and improve the accuracy of these bottom-up emission estimates, inventories are increasingly using information from high-resolution satellite retrievals, particularly for major cities, large-area sources, natural sources, and large point sources (e.g., M. Li et al., 2017a; McLinden et al., 2016; Streets et al., 2013; van der Werf et al., 2017; Beirle et al., 2011; McLinden et al., 2012; Lamsal et al., 2011; Zheng et al., 2019; Elguindi et al., 2020). For example, both the $\mathrm{CEDS}_{\mathrm{Hoesly}}$ and $\mathrm{CEDS}_{\mathrm{GBD}-\mathrm{MAPS}}$ inventories incorporate $\mathrm{SO}_{2}$ emission estimates derived using satellite retrievals in McLinden et al. (2016) to account for previously missing $\mathrm{SO}_{2}$ point sources in the CEDS 1B2_Fugitive-petr-and-gas sector (described further in the supplement of Hoesly et al., 2018), with additional use of satellite data planned for a future CEDS core release. With the continued advancement of satellite retrievals, the development of source- and sector-

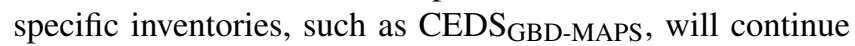
to provide new opportunities for the application of new satellite-based inventories, which will aid in the quantification of spatial and temporal emissions from distinct sources associated with specific sectors and fuel types that may not be accurately estimated using conventional bottom-up approaches.

\subsubsection{Uncertainties in regional-level scaling inventories}

Similar to the CEDS Hoesly inventory, the CEDS $_{\text {GBD-MAPS }}$ emissions will also reflect the uncertainties associated with the inventories used for the scaling procedure. The inventories with the largest impact on the $\mathrm{CEDS}_{\mathrm{GBD} \text {-MAPS }}$ emission uncertainties relative to the CEDS $_{\text {Hoesly }}$ inventory will be those from China from Zheng et al. (2018), the DICE-Africa emission inventory from Marais and Wiedinmyer (2016), and the SMoG-India inventory from Venkataraman et al. (2018). While formal uncertainty analyses were not performed for all of these inventories, similar bottom-up methods used in these studies will result in similar sources of uncertainties (activity and emission factors) as the global inventories. For example, Zheng et al. (2018) state that the largest sources of uncertainty are the accuracy and availability of underlying data (reviewed in M. Li et al., 2017b) and that the levels of uncertainty for China emissions between 2010 and 2017 are expected to be similar to previous national-level bottom-up inventories derived using similar data sources and methodology, such as Zhao et al. (2011), Lu et al. (2011), and Zhang et al. (2009). Similar to global inventories, these previous regional studies estimate much lower levels of uncertainty for $\mathrm{SO}_{2}$ and $\mathrm{NO}_{x}( \pm 16 \%$ and $-13 \%$ to $+37 \%$, respectively) than for $\mathrm{CO}(70 \%)$ and $\mathrm{OC}$ and $\mathrm{BC}$ emissions $(-43 \%$ to $+258 \%$ and $-43 \%$ to $+208 \%$, respectively). Some sectors in China and other regions are particularly uncertain, as discussed further below.

Regional and national inventories, however, have the added benefit of using local knowledge to reduce potential uncertainties in emission factors and missing emission sources. For example, Marais and Wiedinmyer (2016) note that the DICE-Africa emissions are uncertain due to gaps in fuel consumption data. This inventory, however, also includes sources frequently missing in global inventories such as widespread diesel and petrol generator use, kerosene use, and ad hoc oil refining and have used emission factors for on-road car and natural-gas flaring that are more representative of the inefficient fuel combustion conditions in Africa (Marais and Wiedinmyer, 2016; Marais et al., 2019). As dis-

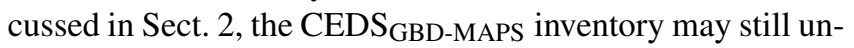
derestimate total emissions from some of these sources (up to $11 \%$ in 2013; Sect. 2.2.3) but otherwise will have uncertainties for total Africa emissions similar to the DICEAfrica inventory. For emissions in India, uncertainties also arise from missing fuel consumption data and the application of non-local or uncertain emission factors. Venkataraman et al. (2018), however, is one of the few studies to present a detailed uncertainty analysis of their inventory and use the propagation of source-specific activity data and emission factors to estimate that total emission uncertainties are smaller for $\mathrm{SO}_{2}(-20 \%$ to $24 \%)$ than for $\mathrm{NO}_{x}(-65 \%$ to $125 \%)$ and NMVOCs $(-44 \%$ to $+66 \%)$. While uncertainties are not explicitly reported for $\mathrm{OC}$ and $\mathrm{BC}$ emissions, Fig. 1 in Venkataraman et al. (2018) indicates that uncertainties in these emissions are between $-60 \%$ and $+95 \%$, consistent with $\mathrm{BC}$ and $\mathrm{OC}$ uncertainties reported in other bottom-up inventories. We also note the ongoing work to improve the accuracy of highly uncertain emission sectors in a 
future release of the SMoG-India inventory through the CarbOnaceous AerosoL Emissions, Source apportionment and ClimatE impacts (COALESCE) project (Venkataraman et al., 2020).

In addition to uncertainties in the scaling inventory emissions, uncertainties are also introduced by the

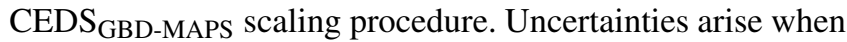
mapping sectoral- and fuel-specific (when available) emissions between inventories (as discussed previously) as well as in the application of the calculated scaling factors outside the range of available scaling inventory years. For example, the implied CO EFs in Fig. S2 highlight one case in China where the EFs for oil and gas combustion in the on-road transport sector peak in 1999 at a value over 3 times larger than EFs in all other top-emitting countries. For China specifically, the calculated scaling factors for the year 2010 (earliest scaling inventory year) are applied to emissions from all years prior, which was calculated as a value of $\sim 1.58$ for the on-road transport sector. The implied EF of $\sim 1.8 \mathrm{~g} \mathrm{~g}^{-1}$ for this sector in 2003 (Fig. S2) suggests that the SF from 2010 may not be representative of emissions during this earlier time period. We do note, however, that the 1999 peak in total CO emissions in China (Fig. S9) is driven by the IEA energy data and is consistent with the $\mathrm{CEDS}_{\text {Hoesly }}$ inventory (Hoesly et al., 2018). In contrast, EFs from this sector in China after the year 2010 agree with the magnitude and trends found in other countries, further indicating that the scaling factors are most appropriate for years with overlapping inventory data. Other similar examples include coal energy emissions of $\mathrm{SO}_{2}$ in Thailand (Fig. S2). In this case, the REAS scaling inventory spans the years 2000-2008. The default EFs for the energy sector, however, independently decrease between 1997 and 2001. As a result, when the implied EF of 3.3 for the year 2000 is applied to all historical energy emissions, the implied EFs prior to 1997 become an order of magnitude larger than those in nearly all other top-emitting countries (Fig. S2). Overall, the applicability of the scaling factors to emissions in years outside the available scaling inventory years remains uncertain due to real historical changes in activity, fuel-use, and emissions mitigation strategies. These uncertainties, however, vary by compound and sector as, for example, there are no similar peaks in onroad emissions for compounds other than CO in China.

Though the inclusion of these regional inventories can improve the accuracy of the global CEDS system (particularly during years with overlapping data), Hoesly et al. (2018) note that large uncertainties may still persist, even in developed countries with stringent reporting standards. In the US for example, it has been suggested that compared to the US National Emissions Inventory (US NEI), total $\mathrm{NO}_{x}$ emissions from on-road and industrial sources in some regions may be overestimated by up to a factor of 2 (e.g., Travis et al., 2016). In addition, $\mathrm{NH}_{3}$ emissions in agricultural regions in winter may be underestimated by a factor of 1.6 to 4.4 (Moravek et al., 2019), and national and regional emissions of NMVOCs from oil and gas extraction regions, solvents, and the use of personal care products may also be underestimated by up to a factor of 2 (McDonald et al., 2018; Ahmadov et al., 2015).

\subsubsection{Uncertainties in sectoral and fuel contributions}

Emissions reported as a function of individual source sectors are typically considered to have higher levels of uncertainty than those reported as country totals due to the cancelation of compounding errors (Schöpp et al., 2005). Source sectors with the largest levels of uncertainty in CEDS GBD-MAPS $_{\text {esti- }}$ mates are generally consistent with other inventories, which include waste burning, residential emissions, and agricultural processes (Hoesly et al., 2018). This higher level of sectoral uncertainty is reflected in the relatively larger uncertainties discussed above in global emissions of $\mathrm{OC}, \mathrm{BC}$, and $\mathrm{NH}_{3}$ relative to other gas-phase species. In general, uncertainties from these sources are larger due to the difficulty in accurately tracking energy consumption statistics and uncertainties in the variability in source-specific emission factors, which will depend on local operational and environmental conditions. For example, residential emission factors from heating and cooking vary depending on technology used and operational conditions (e.g., Venkataraman et al., 2018; Carter et al., 2014; Jayarathne et al., 2018), while soil $\mathrm{NO}_{x}$ emissions and $\mathrm{NH}_{3}$ from wastewater and agriculture result from biological processes that depend on local practices and environmental conditions (e.g., Chen et al., 2012; Paulot et al., 2014). While uncertainties are not always reported at the sectoral level, Venkataraman et al. (2018) do report that industry emissions of $\mathrm{NO}_{x}$ and NMVOCs in the SMoG-India inventory actually have larger uncertainties than those from the transportation, agriculture, and residential (NMVOCs only) sectors, while the relative uncertainties for $\mathrm{SO}_{2}$ emissions follow the opposite trend. For emissions of total fine particulate matter, Venkataraman et al. (2018) estimate that the sectors with the largest uncertainties are the residential and industry emissions. Similarly, Lei et al. (2011) estimate that $\mathrm{BC}$ and $\mathrm{OC}$ emissions from the residential sector in China have the largest inventory uncertainties, while Zhang et al. (2009) and Zheng et al. (2018) also report relatively smaller uncertainties from power plants and heavy industry in China due to known activity data, local emission factors, pollution control technologies, and direct emissions monitoring. Overall, the mosaic scaling procedure in the CEDS system will result in similar levels of uncertainties as these regional scaling inventories.

With the release of fuel-specific information in the CEDS $_{\text {GBD-MAPS }}$ inventory, additional uncertainty in the allocation of fuel types is expected. In this work, activity data at the detailed sector and fuel level are taken from the IEA World Energy statistics (IEA, 2019) and are subject to the same sources of uncertainty. Emission factors for CEDS working sectors and fuels (Table S2) are derived from GAINS. In general, emissions from solid biofuel combus- 
tion are considered to be less certain than fossil fuel consumption due to large uncertainties in both fuel consumption and EFs, particularly in the residential and commercial sectors. For example, by combining information from EDGAR v4.3.2 (Crippa et al., 2018) and a recent TNO-RWC (Netherland Organization for Applied Scientific Research, Residential Wood Combustion) inventory from Denier van der Gon et al. (2015), Crippa et al. (2019) estimated that uncertainties in emissions from wood combustion in the residential sector in Europe are between $200 \%$ and $300 \%$ for OC, BC, and $\mathrm{NH}_{3}$. Crippa et al. (2019) also report that these uncertainties are largely driven by uncertainties in regional emission factors as uncertainties in biofuel consumption are estimated to be between $38.9 \%$ and $59.5 \%$. These uncertainties, however, are still larger than those estimated for fossil fuel consumption in many countries. As noted in Hoesly et al. (2018), increased levels of uncertainty in fossil fuel emissions are also expected in some countries, including the consumption and emission factors related to coal combustion in China (e.g., Liu et al., 2015; Guan et al., 2012; Hong et al., 2017), which will have the largest impacts on $\mathrm{CEDS}_{\mathrm{GBD}-\mathrm{MAPS}}$ emissions of $\mathrm{NO}_{x}, \mathrm{SO}_{2}$, and BC. Specific to the CEDS inventory, additional uncertainties may arise from the potential underestimation of total coal, oil and gas, and biofuel emissions associated with fugitive emissions and gas flaring in the energy sector as well as waste incineration in the waste sector. As discussed above and in Hoesly et al. (2018), fugitive emissions are highly uncertain. The degree of underestimation in combustion fuel contributions will be dependent on the fractional contribution of process-level emissions in these sectors relative to those from coal, biofuel, and oil and gas combustion (Table S8). Additional uncertainties in the gridded fuel-specific products are discussed in the following section.

\subsubsection{Uncertainties and limitations in gridded emission fluxes}

As noted in Sect. 2.1, global gridded CEDS ${ }_{\text {GBD-MAPS }}$ emission fluxes are provided to facilitate their use in earth system models. Relative to the reported country-total emission files, additional uncertainties are introduced in the $0.5^{\circ} \times 0.5^{\circ}$ global gridded $\mathrm{CEDS}_{\mathrm{GBD}-\mathrm{MAPS}}$ emission fluxes through the use of source-specific spatial gridding proxies in CEDS Step 5. Historical spatial distributions within each country are largely based on normalized gridded emissions from the EDGAR v4.3.2 inventory. These spatial proxies are held constant after 2012, which serves to increase the uncertainties in spatial allocation in large countries in recent years. The magnitude of this uncertainty will depend on the specific compound and sector. For example, gridded emissions from the energy sector will not reflect the closure or fuel-switching of individual coal-fired power stations after 2012. Changes in total country-level emissions from this sector and fuel type, however, will be accurately reflected in the total country- level emission files. This source of uncertainty is also present in the CEDS Hoesly inventory. An additional source of uncertainty in the gridded emissions is that the same spatial allocations are applied uniformly across emissions of all fuel types within each source sector. This may lead to additional uncertainties if, for example, emissions from the use of coal, biofuel, oil and gas, and remaining sources within each sector are spatially distinct. These uncertainties, however, do not impact the final country-level CEDS ${ }_{\text {GBD-MAPS }}$ products because they are not gridded.

Lastly, while CEDS $_{\text {GBD-MAPS }}$ emissions provide a global inventory of key atmospheric pollutants, this inventory does not include a complete set of sources or species required for GCM or CTM simulations of atmospheric chemical processes. As noted in Sect. 2, neither $\mathrm{CEDS}_{\text {Hoesly }}$ nor CEDS $_{\text {GBD-MAPS }}$ estimates include emissions from large or small open fires, which must be supplemented with additional open-burning inventories, such as the Global Fire Emissions Database (GFED, 2019; van der Werf et al., 2017) or Fire INventory from NCAR (FINN, 2018; Wiedinmyer et al., 2011). In addition, simulations of atmospheric chemistry require emissions from biogenic sources, typically supplied from inventories, such as the Model of Emissions of Gases and Aerosols from Nature (MEGAN, 2019; Guenther et al., 2012). Other sources to consider in atmospheric simulations include volcanic emissions, sea spray, and windblown dust. In addition, the CEDS system does not include dust emissions from windblown and anthropogenic sources such as roads, combustion, or industrial process. Anthropogenic dust sources may contribute up to $\sim 10 \%$ of total fine-dust emissions in recent years and are important to consider when simulating concentrations of total atmospheric particulate matter (Philip et al., 2017). Lastly, the $\mathrm{CEDS}_{\mathrm{GBD}-\mathrm{MAPS}}$ inventory also excludes emissions of greenhouse gases such as methane and carbon dioxide $\left(\mathrm{CH}_{4}, \mathrm{CO}_{2}\right)$. These compounds were previously included through 2014 in the $\mathrm{CEDS}_{\text {Hoesly inventory. }}$

\section{Data availability}

The source code for the $\mathrm{CEDS}_{\mathrm{GBD}-\mathrm{MAPS}}$ system is available on GitHub (https://github.com/emcduffie/ CEDS/tree/CEDS_GBD-MAPS, last access: 1 December 2020, and https://doi.org/10.5281/zenodo.3865670; McDuffie et al., 2020a). To run the CEDS system, users are required to first purchase the proprietary energy consumption data from the IEA (World Energy Statistics; https://www.iea.org/subscribe-to-data-services/ world-energy-balances-and-statistics, last access: 1 December 2020). The IEA is updated annually and provides the most comprehensive global energy statistics available to date. All additional input data are available in the CEDS GitHub repository.

Final products from the $\mathrm{CEDS}_{\mathrm{GBD}-\mathrm{MAPS}}$ system include total annual emissions for each country as well as 
monthly global gridded $\left(0.5^{\circ} \times 0.5^{\circ}\right)$ emission fluxes for the years 1970-2017. Both products are available on Zenodo (https://doi.org/10.5281/zenodo.3754964; McDuffie et al., 2020c) and report total emissions and gridded fluxes as a function of 11 final source sectors and four fuel categories (total coal, solid biofuel, oil + gas, process). Time series of annual country-total emissions from 1970-2017 are provided in units of $\mathrm{kt}^{-1}$ and provide $\mathrm{NO}_{x}$ emissions as $\mathrm{NO}_{2}$. These data do not speciate total NMVOCs into sub-VOC classes. In these .csv files, total anthropogenic emissions for each country are calculated as the sum of all sectors and fuel types within each country. For the global gridded products, emission fluxes of each compound as a function of 11 sectors and four fuel types are available for each year in individual netCDF files. These data are in units of $\mathrm{kg} \mathrm{m}^{-2} \mathrm{~s}^{-1}$ and provide $\mathrm{NO}_{x}$ emissions as NO. Total NMVOCs are speciated into 25 sub-VOC classes as described in Sect. 2. For consistency with the CEDS data released for CMIP6 (CEDS, 2017a, b), gridded anthropogenic fluxes for 1970-2017 are additionally available in the CMIP6 format. Note that $\mathrm{NO}_{x}$ is in units of $\mathrm{NO}_{2}$ in this format. Additional file format details are in the README.txt file in the Zenodo repository (https://doi.org/10.5281/zenodo.3754964, McDuffie et al., 2020c).

To provide an example of the products and file formats available for download from the full $\mathrm{CEDS}_{\mathrm{GBD}-\mathrm{MAPS}}$ repository, we have also prepared an additional data "snapshot" inventory that provides emissions in all three file formats described above for the 2014-2015 time period (McDuffie et al., 2020b). The gridded data are provided as monthly averages for the December 2014-February 2015 time period, while the annual data include total emissions from both 2014 and 2015. These data can be downloaded from https://doi.org/10.5281/zenodo.3833935 (McDuffie et al., 2020b) and are further described in the associated README.txt file.

\section{Summary and conclusions}

We described the new CEDS $_{\text {GBD-MAPS }}$ global emission inventory for key atmospheric reactive gases and carbonaceous aerosol from 11 anthropogenic emission sectors and four fuel types (total coal, solid biofuel, liquid-fuel and natural-gas combustion, and remaining process-level emissions) over the time period from 1970-2017. The CEDS ${ }_{\text {GBD-MAPS }}$ inventory was derived from an updated version of the Community Emissions Data System, which incorporates updated activity data for combustion- and process-level emission sources, updated scaling inventories, the added scaling of $\mathrm{BC}$ and $\mathrm{OC}$ emissions, and adjustments to the aggregation and gridding procedures to enable the extension of emission estimates to 2017 while retaining sectoral and fuel type information. We incorporated new regional scaling inventories for India and Africa; as a result default $\mathrm{CEDS}_{\mathrm{GBD} \text {-MAPs }}$ emissions are now lower than previous CEDS $_{\text {Hoesly }}$ estimates for all compounds in these regions other than NMVOCs in Africa and $\mathrm{BC}$ in India. These updates improve the agreement of CEDS $_{\text {GBD-MAPS }}$ Africa emissions with those from EDGAR v4.3.2 as well as the agreement of all India emissions other than BC with both the EDGAR (2012) and GAINS (2010) inventories. Scaling default BC and OC estimates reduces these global emissions by up to $21 \%$ and $28 \%$, respectively, relative to the CEDS Hoesly $_{\text {inventory. This reduction }}$ improves CEDS ${ }_{\text {GBD-MAPS }}$ agreement with both GAINS and EDGAR global estimates of BC and OC, particularly in recent years. The resulting $\mathrm{CEDS}_{\mathrm{GBD}-\mathrm{MAPS}}$ inventory provides the most contemporary global emission inventory to date for these key atmospheric pollutants and is the first to provide their global emissions as a function of both detailed source sector and fuel type.

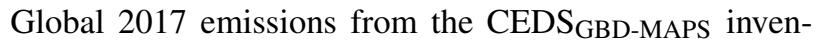
tory suggest that coal and oil and gas combustion in both the energy and industry sectors are the largest global sources of $\mathrm{SO}_{2}$ emissions, while $\mathrm{CO}$ emissions are primarily from on-road transportation and biofuel combustion in the residential sector. Global emissions of both compounds peak by 1990 and decrease until 2017 as a result of continuous reductions in on-road transport emissions in Europe and North America as well as reductions in coal combustion emissions from the energy and industry sectors across these regions and in China. In contrast, global $\mathrm{NO}_{x}, \mathrm{BC}$, and $\mathrm{OC}$ emissions peak later, between 2010 and 2012, but also decrease until 2017 due to reductions in North America, Africa, and China. Dominant sources of $\mathrm{NO}_{x}$ in 2017 are from international shipping, energy, industry, and on-road transportation sectors. Major sources of $\mathrm{BC}$ emissions are from residential biofuel combustion and on-road transportation, while dominant $\mathrm{OC}$ sources are from the residential biofuel and the waste sector. Outside of international shipping, China is the largest regional source of global emissions of all compounds other than NMVOCs. As emissions in North America, Europe, and China continue to decrease, global emissions of $\mathrm{NO}_{x}, \mathrm{CO}, \mathrm{SO}_{2}, \mathrm{BC}$, and $\mathrm{OC}$ will increasingly reflect emissions in rapidly growing regions such as Africa, India, and countries throughout Asia, Latin America, and the Middle East. Lastly, in contrast to other compounds, global emissions of NMVOCs and $\mathrm{NH}_{3}$ continuously increase over the entire time period. These increases are predominantly due to increases in agricultural $\mathrm{NH}_{3}$ emissions in nearly all world regions as well as NMVOCs from increased waste, energy sector, and solvent use emissions. In 2017, global emissions of these compounds had the largest regional contributions from India, China, and countries throughout Africa, Asia, and the Pacific.

Historical global emission trends in the $\mathrm{CEDS}_{\mathrm{GBD}-\mathrm{MAPS}}$ inventory are generally similar to those in three other global inventories: $\mathrm{CEDS}_{\text {Hoesly }}$, EDGAR v4.3.2, and ECLIPSE v5a

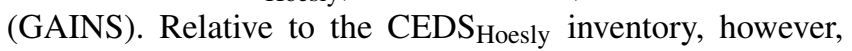
CEDS $_{\text {GBD-MAPS }}$ emissions diverge in recent years, particu- 
larly for $\mathrm{NO}_{x}, \mathrm{CO}, \mathrm{SO}_{2}, \mathrm{BC}$, and $\mathrm{OC}$ emissions. In addition to the use of updated underlying activity data in the CEDS $_{\text {GBD-MAPS }}$ inventory, emissions of these compounds were most impacted by the updated CEDS scaling inventories, including those for China, India, and Africa. These same updates also contribute to the different trends in global $\mathrm{NO}_{x}$, $\mathrm{CO}$, and $\mathrm{SO}_{2}$ emissions after 2010 between $\mathrm{CEDS}_{\mathrm{GBD}-\mathrm{MAPS}}$ and the GAINS and EDGAR inventories. Global emissions between 1970 and 2017 from the CEDS ${ }_{\text {GBD-MAPS inven- }}$ tory are generally smaller than the CEDS $_{\text {Hoesly }}$ emissions for all compounds other than NMVOCs and are consistently higher than all emissions from EDGAR v4.3.2. Global CEDS $_{\text {GBD-MAPS }}$ emissions are also larger than GAINS emissions, except for $\mathrm{BC}$ and select years of $\mathrm{SO}_{2}$ emissions.

Due to similar bottom-up methodologies and the use of EDGAR v4.3.2 data in the CEDS system, country-

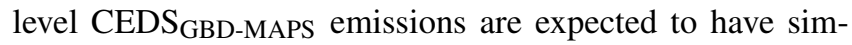
ilar sources and magnitudes of uncertainty as those in the

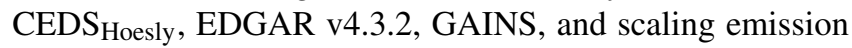
inventories. These inventories consistently predict the smallest uncertainties in emissions of $\mathrm{SO}_{2}$ and the largest for emissions of $\mathrm{NH}_{3}, \mathrm{OC}$, and $\mathrm{BC}$. The latter three compounds largely depend on accurate knowledge of activity data and emission factors for small scattered sources that vary by location, combustion technologies used, and environmental conditions. Uncertainties in the sectoral and fuel allocations in CEDS $_{\text {GBD-MAPS }}$ emissions will also generally follow the uncertainties in the CEDS v2019-12-23 system and will largely depend on the accuracy of the fuel allocations for combustion sources in the underlying IEA activity data. Gridded CEDS $_{\text {GBD-MAPS }}$ emissions also have uncertainties associated with the accuracy of the normalized spatial emission distributions from EDGAR v4.3.2, which are equally applied to all four fuel categories and are held constant after 2012.

Contemporary global emission estimates with detailed sector- and fuel-specific information are vital for quantifying the anthropogenic sources of air pollution and mitigating the resulting impacts on human health, the environment, and society. While bottom-up methods can provide sector-specific emission estimates, previous global inventories of multiple compounds and sources have lagged in time and do not provide fuel-specific emissions for multiple compounds at the global scale. To address this community need, the CEDS ${ }_{\text {GBD-MAPS }}$ inventory utilizes the CEDS system (v2019-12-23) to provide emissions of seven key atmospheric pollutants with detailed sectoral and fuel type information, extended to the year 2017. Due to the direct and secondary contribution of these reactive gases and carbonaceous aerosol to ambient air pollution, contemporary gridded and country-level emissions with both sector and fuel type information can provide new insights necessary to motivate and develop effective strategies for emission reductions and air pollution mitigation around the world.

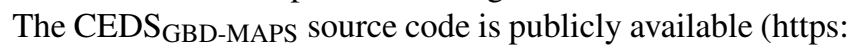
//github.com/emcduffie/CEDS/tree/CEDS_GBD-MAPS and https://doi.org/10.5281/zenodo.3865670, McDuffie et al., 2020a), and both country-total and global gridded emissions from the 2020_v1 version of this dataset are publicly available at Zenodo with the following DOI: https://doi.org/10.5281/zenodo.3754964 (McDuffie et al., 2020c).

Supplement. The supplement for this article describes a list of known inventory issues at the time of submission as well as a number of additional CEDS $_{\mathrm{GBD}-\mathrm{MAPS}}$ details, tables and figures, and data sources, including the following: Boden et al. (2016, 2017), BP (2015), Doxsey-Whitfield et al. (2015), ECJRC/PBL (2012, 2016), EIA (2019), IEA (2015), Klein Goldewijk et al. (2011), Sharma et al. (2019), Stohl et al. (2015), The World Bank (2016), UN (2014, 2015), Wiedinmyer et al. (2014), Commoner et al. (2000), Reyna-Bensusan et al. (2018), Nagpure et al. (2015), Meidiana and Gamse (2010), and US EPA, (2006). The supplement related to this article is available online at: https://doi.org/10.5194/essd-12-3413-2020-supplement.

Author contributions. EEM prepared the manuscript with contributions from all co-authors. RVM, MB, and SJS supervised the scientific content of this publication. EEM led the development

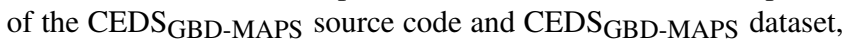
with significant contributions from SJS and PO as well as supplemental data from $\mathrm{KT}, \mathrm{CV}$, and EAM.

Competing interests. The authors declare that they have no conflict of interest.

Acknowledgements. We thank Christine Wiedinmyer and Qiang Zhang for their respective contributions to the DICE-Africa and updated China nation-level inventories, used here for scaling CEDS $_{\text {GBD-MAPS }}$ emissions. CEDS utilizes many sources of input data, and we are grateful for these contributions from a large number of research teams.

Financial support. This research has been supported by the Health Effects Institute (grant no. 4965/19-1).

Review statement. This paper was edited by David Carlson and reviewed by Hugo Denier van der Gon and one anonymous referee.

\section{References}

ADE: Australian Department of the Environment: National Pollution Inventory, 2017/2018, http://www.npi.gov.au/npidata/ action/load/advance-search (lastaccess: 15 August 2019), 2019.

Ahmadov, R., McKeen, S., Trainer, M., Banta, R., Brewer, A., Brown, S., Edwards, P. M., de Gouw, J. A., Frost, G. J., Gilman, J., Helmig, D., Johnson, B., Karion, A., Koss, A., Langford, 
A., Lerner, B., Olson, J., Oltmans, S., Peischl, J., Pétron, G., Pichugina, Y., Roberts, J. M., Ryerson, T., Schnell, R., Senff, C., Sweeney, C., Thompson, C., Veres, P. R., Warneke, C., Wild, R., Williams, E. J., Yuan, B., and Zamora, R.: Understanding high wintertime ozone pollution events in an oil- and natural gasproducing region of the western US, Atmos. Chem. Phys., 15, 411-429, https://doi.org/10.5194/acp-15-411-2015, 2015.

Ainsworth, E. A.: Understanding and improving global crop response to ozone pollution, Plant J., 90, 886-897, https://doi.org/10.1111/tpj.13298, 2017.

Amann, M., Bertok, I., Borken-Kleefeld, J., Cofala, J., Heyes, C., Höglund-Isaksson, L., Klimont, Z., Nguyen, B., Posch, M., Rafaj, P., Sandler, R., Schöpp, W., Wagner, F., and Winiwarter, W.: Cost-effective control of air quality and greenhouse gases in Europe: Modeling and policy applications, Environ. Modell. Softw., 26, 1489-1501, https://doi.org/10.1016/j.envsoft.2011.07.012, 2011.

Amann, M., Bertok, I., Borken-Kleefeld, J., Cofala, J., Heyes, C., Hoglund-Isaksson, L., Kiesewetter, G., Klimont, Z., Schopp, W., Vellinga, N., and Winiwarter, W.: Adjusted historic emission data, projections, and optimized emission reduction targets for 2030 - a comparison with COM data 2013, IIASA, Laxenburg, Austria, available at: http://ec.europa.eu/environment/air/ pdf/review/TSAP_16a.pdf (last access: 15 January 2018), 2015.

Argentina UNFCCC Submission: Argentinian Inventory 19902012, submitted to UNFCCC, 2016.

Avnery, S., Mauzerall, D. L., Liu, J., and Horowitz, L. W.: Global crop yield reductions due to surface ozone exposure: 1. Year 2000 crop production losses and economic damage, Atmos. Environ., 45, 2284-2296, https://doi.org/10.1016/j.atmosenv.2010.11.045, 2011.

Behera, S. N., Sharma, M., Aneja, V. P., and Balasubramanian, R.: Ammonia in the atmosphere: a review on emission sources, atmospheric chemistry and deposition on terrestrial bodies, Environ. Sci. Pollut. R., 20, 8092-8131, https://doi.org/10.1007/s11356-013-2051-9, 2013.

Beirle, S., Boersma, K. F., Platt, U., Lawrence, M. G., and Wagner, T.: Megacity Emissions and Lifetimes of Nitrogen Oxides Probed from Space, Science, 333, 1737, https://doi.org/10.1126/science.1207824, 2011.

Boden, T. A., Marland, G., and Andres, R. J.: Global, Regional, and National Fossil-Fuel $\mathrm{CO}_{2}$ Emissions, Carbon Dioxide Information Analysis Center, US Department of Energy, Oak Ridge, USA, 2016.

Boden, T. A., Marland, G., and Andres, R. J.: Global, Regional, and National Fossil-Fuel $\mathrm{CO}_{2}$ Emissions, Carbon Dioxide Information Analysis Center, US Department of Energy, Oak Ridge, USA, https://doi.org/10.3334/CDIAC/00001_V2017, 2017.

Bond, T. C., Streets, D. G., Yarber, K. F., Nelson, S. M., Woo, J.-H., and Klimont, Z.: A technology-based global inventory of black and organic carbon emissions from combustion, J. Geophys. Res., 109, D14203, https://doi.org/10.1029/2003JD003697, 2004.

Dong, R., Jogani, R., Jung, S., Roden, C., Streets, D. G., and Trautmann, N. M.: Historical emissions of black and organic carbon aerosol from energy-related combustion, 1850-2000, Global Biogeochem. Cycles, 21, GB2018, https://doi.org/10.1029/2006GB002840, 2007.
Bond, T. C., Doherty, S. J., Fahey, D. W., Forster, P. M., Berntsen, T., DeAngelo, B. J., Flanner, M. G., Ghan, S., Kärcher, B., Koch, D., Kinne, S., Kondo, Y., Quinn, P. K., Sarofim, M. C., Schultz, M. G., Schulz, M., Venkataraman, C., Zhang, H., Zhang, S., Bellouin, N., Guttikunda, S. K., Hopke, P. K., Jacobson, M. Z., Kaiser, J. W., Klimont, Z., Lohmann, U., Schwarz, J. P., Shindell, D., Storelvmo, T., Warren, S. G., and Zender, C. S.: Bounding the role of black carbon in the climate system: A scientific assessment, J. Geophys. Res.-Atmos., 118, 5380-5552, https://doi.org/10.1002/jgrd.50171, 2013.

BP: BP Statistical Review of World Energy, available at: https: //www.bp.com/statisticalreview (last access: 15 January 2018), 2015.

BP: Statistical Review of World Energy: 2019, available at: https://www.bp.com/content/dam/bp/business-sites/en/ global/corporate/pdfs/energy-economics/statistical-review/ bp-stats-review-2019-full-report.pdf (last access: 23 January 2020), 2019.

Brock, C. A., Washenfelder, R. A., Trainer, M., Ryerson, T. B., Wilson, J. C., Reeves, J. M., Huey, L. G., Holloway, J. S., Parrish, D. D., Hübler, G., and Fehsenfeld, F. C.: Particle growth in the plumes of coal-fired power plants, J. Geophys. Res.-Atmos., 107, D124155, https://doi.org/10.1029/2001JD001062, 2002.

Carter, E. M., Shan, M., Yang, X., Li, J., and Baumgartner, J.: Pollutant Emissions and Energy Efficiency of Chinese Gasifier Cooking Stoves and Implications for Future Intervention Studies, Environ. Sci. Technol., 48, 6461-6467, https://doi.org/10.1021/es405723w, 2014.

Castellanos, P. and Boersma, K. F.: Reductions in nitrogen oxides over Europe driven by environmental policy and economic recession, Sci. Rep.-UK, 2, 265, https://doi.org/10.1038/srep00265, 2012.

CEDS: v2017_08_30, available at: https://esgf-node.llnl.gov/ search/input4mips/ (last access: 7 January 2020), 2017a.

CEDS: v2017_10_05, available at: https://esgf-node.llnl.gov/ search/input4mips/ (last access: 7 January 2020), 2017b.

Chameides, W. L.: The photochemical role of tropospheric nitrogen oxides, Geophys. Res. Lett., 5, 17-20, https://doi.org/10.1029/GL005i001p00017, 1978.

Chen, Y., Roden, C. A., and Bond, T. C.: Characterizing Biofuel Combustion with Patterns of Real-Time Emission Data (PaRTED), Environ. Sci. Technol., 46, 6110-6117, https://doi.org/10.1021/es3003348, 2012.

Commoner, B., Bartlett, P. W., Eisl, H., and Couchot, K.: Air Transport of Dioxin from North American Sources to Ecologically Vulnerable Receptors in Nunavut, Arctic Canada: Final Report to the North American Commission for Environmental Cooperation, available at: http://www3.cec.org/islandora/en/item/1596long-range-air-transport-dioxin-from-north-american-sourcesecologically-vulnerable-en.pdf (last access: 25 April 2020), 2000.

Crippa, M., Guizzardi, D., Muntean, M., Schaaf, E., Dentener, F., van Aardenne, J. A., Monni, S., Doering, U., Olivier, J. G. J., Pagliari, V., and Janssens-Maenhout, G.: Gridded emissions of air pollutants for the period 1970-2012 within EDGAR v4.3.2, Earth Syst. Sci. Data, 10, 1987-2013, https://doi.org/10.5194/essd-10-1987-2018, 2018.

Crippa, M., Janssens-Maenhout, G., Guizzardi, D., Van Dingenen, R., and Dentener, F.: Contribution and uncertainty 
of sectorial and regional emissions to regional and global $\mathrm{PM}_{2.5}$ health impacts, Atmos. Chem. Phys., 19, 5165-5186, https://doi.org/10.5194/acp-19-5165-2019, 2019.

Crutzen, P. J.: The influence of nitrogen oxides on the atmospheric ozone content, Q. J. Roy. Meteor. Soc., 96, 320-325, https://doi.org/10.1002/qj.49709640815, 1970.

de Gouw, J. A., Parrish, D. D., Frost, G. J., and Trainer, M.: Reduced emissions of $\mathrm{CO}_{2}, \mathrm{NO}_{x}$, and $\mathrm{SO}_{2}$ from US power plants owing to switch from coal to natural gas with combined cycle technology, Earths Future, 2, 75-82, https://doi.org/10.1002/2013EF000196, 2014.

Denier van der Gon, H. A. C., Bergström, R., Fountoukis, C., Johansson, C., Pandis, S. N., Simpson, D., and Visschedijk, A. J. H.: Particulate emissions from residential wood combustion in Europe - revised estimates and an evaluation, Atmos. Chem. Phys., 15, 6503-6519, https://doi.org/10.5194/acp15-6503-2015, 2015.

DICE-Africa: DICE-Africa User Manual, available at: https:// www2.acom.ucar.edu/modeling/dice-africa (last access: 9 January 2020), 2016.

Doxsey-Whitfield, E., MacManus, K., Adamo, S. B., Pistolesi, L., Squires, J., Borkovska, O., and Baptista, S. R.: Taking Advantage of the Improved Availability of Census Data: A First Look at the Gridded Population of the World, Version 4, Papers in Applied Geography, 1, 226-234, https://doi.org/10.1080/23754931.2015.1014272, 2015.

Duncan, B. N., Yoshida, Y., de Foy, B., Lamsal, L. N., Streets, D. G., Lu, Z., Pickering, K. E., and Krotkov, N. A.: The observed response of Ozone Monitoring Instrument (OMI) $\mathrm{NO}_{2}$ columns to $\mathrm{NO}_{x}$ emission controls on power plants in the United States: 2005-2011, Atmos. Environ., 81, 102-111, https://doi.org/10.1016/j.atmosenv.2013.08.068, 2013.

ECCC: Environment and Climate Change Canada, EN_APEICanada, Canada's 2019 Air Pollutant Emissions Inventory, available at: http://data.ec.gc.ca/data/substances/monitor/ canada-s-air-pollutant-emissions-inventory/APEI_Tables_ Canada_Provinces_Territories/?lang, last access: 13 August 2019.

EC-JRC: Emissions Database for Global Atmospheric Research (EDGAR), release EDGARv4.3.2, available at: https://edgar. jrc.ec.europa.eu/overview.php?v (last access: 12 August 2019), 2018.

EC-JRC/PBL: Emission Database for Global Atmospheric Research (EDGAR), release EDGAR v4.2 FT2012, available at: http://edgar.jrc.ec.europa.eu (last access: 15 January 2018), 2012.

EC-JRC/PBL: Emission Database for Global Atmospheric Research (EDGAR), release version 4.3.1, available at: http://edgar. jrc.ec.europa.eu/overview.php?v (last access: 15 January 2018), 2016.

EIA: US Energy Information Administration: Table 10.2a: Renewable Energy Cnsumption, Residential and Commercial Sectors, available at: https://www.eia.gov/totalenergy/data/monthly/ \#renewable (last access: 26 August 2019), 2019.

EIA: US Energy Information Administration: Drilling Productivity Report, available at: https://www.eia.gov/petroleum/drilling/, last access: 7 April 2020.

Elguindi, N., Granier, C., Stavrakou, T., Darras, S., Bauwens, M., Cao, H., Chen, C., Denier van der Gon, H. A. C.,
Dubovik, O., Fu, T. M., Henze, D. K., Jiang, Z., Keita, S., Kuenen, J. J. P., Kurokawa, J., Liousse, C., Miyazaki, K., Müller, J. F., Qu, Z., Solmon, F., and Zheng, B.: Intercomparison of Magnitudes and Trends in Anthropogenic Surface Emissions From Bottom-Up Inventories, Top-Down Estimates, and Emission Scenarios, Earths Future, 8, e2020EF001520, https://doi.org/10.1029/2020EF001520, 2020.

EMEP: Officially reported emission data to the European Monitoring and Evaluation Programme: EMEP_NFR14_LEVEL1 data, available at: https://www.ceip.at/ms/ceip_home1/ceip_ home/webdab_emepdatabase/reported_emissiondata/, last access: 19 December 2019.

FAOSTAT: FAOSTAT-Forestry database, available at: http://www. fao.org/forestry/statistics/84922/en/ (last access: 15 January 2018), 2015.

Feng, L., Smith, S. J., Braun, C., Crippa, M., Gidden, M. J., Hoesly, R., Klimont, Z., van Marle, M., van den Berg, M., and van der Werf, G. R.: The generation of gridded emissions data for CMIP6, Geosci. Model Dev., 13, 461-482, https://doi.org/10.5194/gmd-13-461-2020, 2020.

FINN: Fire INventory from NCAR, Version 1.5, available at: http: //bai.acom.ucar.edu/Data/fire/ (last access: 4 March 2020), 2018.

GBD 2017 Risk Factor Collaborators: Global, regional, and national comparative risk assessment of 84 behavioural, environmental and occupational, and metabolic risks or clusters of risks for 195 countries and territories, 1990-2017: a systematic analysis for the Global Burden of Disease Study 2017, The Lancet, 392, 1923-1994, https://doi.org/10.1016/S0140-6736(18)32225$6,2018$.

GBD MAPS Working Group: Burden of Disease Attributable to Coal-Burning and Other Major Sources of Air Pollution in China, Special Report 20, Health Effects Institute, available at: https://www.healtheffects.org/publication/burden-diseaseattributable-coal-burning-and-other-air-pollution-sources-china (last access: 1 December 2020), 2016.

GBD MAPS Working Group: Burden of Disease Attributable to Major Air Pollution Sources in India, Special Report 21, Health Effects Institute available at: https://www.healtheffects. org/publication/gbd-air-pollution-india, (last access: 1 December 2020) 2018.

GFED: Global Fire Emissions Database, available at: http:// globalfiredata.org/index.html (last access: 15 March 2020), 2019.

Gidden, M. J., Riahi, K., Smith, S. J., Fujimori, S., Luderer, G., Kriegler, E., van Vuuren, D. P., van den Berg, M., Feng, L., Klein, D., Calvin, K., Doelman, J. C., Frank, S., Fricko, O., Harmsen, M., Hasegawa, T., Havlik, P., Hilaire, J., Hoesly, R., Horing, J., Popp, A., Stehfest, E., and Takahashi, K.: Global emissions pathways under different socioeconomic scenarios for use in CMIP6: a dataset of harmonized emissions trajectories through the end of the century, Geosci. Model Dev., 12, 14431475, https://doi.org/10.5194/gmd-12-1443-2019, 2019.

Guan, D., Liu, Z., Geng, Y., Lindner, S., and Hubacek, K.: The gigatonne gap in China's carbon dioxide inventories, Nat. Clim. Change, 2, 672-675, https://doi.org/10.1038/nclimate1560, 2012.

Guenther, A. B., Jiang, X., Heald, C. L., Sakulyanontvittaya, T., Duhl, T., Emmons, L. K., and Wang, X.: The Model of Emissions of Gases and Aerosols from Nature version 2.1 
(MEGAN2.1): an extended and updated framework for modeling biogenic emissions, Geosci. Model Dev., 5, 1471-1492, https://doi.org/10.5194/gmd-5-1471-2012, 2012.

Haywood, J. and Boucher, O.: Estimates of the direct and indirect radiative forcing due to tropospheric aerosols: A review, Rev. Geophys., 38, 513-543, https://doi.org/10.1029/1999RG000078, 2000.

Hoesly, R. M., Smith, S. J., Feng, L., Klimont, Z., JanssensMaenhout, G., Pitkanen, T., Seibert, J. J., Vu, L., Andres, R. J., Bolt, R. M., Bond, T. C., Dawidowski, L., Kholod, N., Kurokawa, J.-I., Li, M., Liu, L., Lu, Z., Moura, M. C. P., O'Rourke, P. R., and Zhang, Q.: Historical (1750-2014) anthropogenic emissions of reactive gases and aerosols from the Community Emissions Data System (CEDS), Geosci. Model Dev., 11, 369-408, https://doi.org/10.5194/gmd-11-369-2018, 2018.

Hoesly, R., O'Rourke, P., Braun, C., Feng, L., Smith, S. J., Pitkanen, T., Siebert, J., Vu, L., Presley, M., Bolt, R., Goldstein, B., and Kholod, N.: CEDS: Community Emissions Data System (Version Dec-23-2019), Zenodo, https://doi.org/10.5281/zenodo.3592073, 2019.

Hong, C., Zhang, Q., He, K., Guan, D., Li, M., Liu, F., and Zheng, B.: Variations of China's emission estimates: response to uncertainties in energy statistics, Atmos. Chem. Phys., 17, 1227-1239, https://doi.org/10.5194/acp-17-1227-2017, 2017.

HTAP2: RETRO NMVOC Ratio, available at: http://iek8wikis.iek. fz-juelich.de/HTAPWiki/WP1.1?action (last access: 7 January 2020), 2013.

Huang, G., Brook, R., Crippa, M., Janssens-Maenhout, G., Schieberle, C., Dore, C., Guizzardi, D., Muntean, M., Schaaf, E., and Friedrich, R.: Speciation of anthropogenic emissions of non-methane volatile organic compounds: a global gridded data set for 1970-2012, Atmos. Chem. Phys., 17, 7683-7701, https://doi.org/10.5194/acp-17-7683-2017, 2017.

IEA: World Energy Statistics, available at: http://www.iea.org/ statistics/ (last access: 15 January 2018), 2015.

IEA: World Energy Statistics 2019 Edition, Database Documentation, available at: http://wds.iea.org/wds/pdf/WORLDBES_ Documentation.pdf, last access: 17 September 2019.

IIASA: GAINS - Sulfur content of fuels, available at: http://gains. iiasa.ac.at/models/index.html (last access: 15 January 2018), 2014.

IIASA: ECLIPSE v5a, available at: https://www.iiasa.ac.at/web/ home/research/researchPrograms/air/ECLIPSEv5a.html (last access: 7 January 2020), 2015.

IPCC: Summary for Policy Makers, in: Climate Change 2013: The Physical Science Basis, Contribution of Working Group I to the Fifth Assessment Report of the Intergovernmental Panel on Climate Change, edited by: Stocker, T. F., Qin, D., Plattner, G.-K., Tignor, M., Allen, S. K., Boschung, J., Nauels, Y., Xia, Y., Bex, V., and Midgley, P. M., Cambridge University Press, Cambridge, United Kingdom and New York, USA, 1-29, 2013.

Janssens-Maenhout, G., Crippa, M., Guizzardi, D., Dentener, F., Muntean, M., Pouliot, G., Keating, T., Zhang, Q., Kurokawa, J., Wankmüller, R., Denier van der Gon, H., Kuenen, J. J. P., Klimont, Z., Frost, G., Darras, S., Koffi, B., and Li, M.: HTAP_v2.2: a mosaic of regional and global emission grid maps for 2008 and 2010 to study hemispheric transport of air pollution, Atmos. Chem. Phys., 15, 11411-11432, https://doi.org/10.5194/acp-15-11411-2015, 2015.
Jayarathne, T., Stockwell, C. E., Bhave, P. V., Praveen, P. S., Rathnayake, C. M., Islam, Md. R., Panday, A. K., Adhikari, S., Maharjan, R., Goetz, J. D., DeCarlo, P. F., Saikawa, E., Yokelson, R. J., and Stone, E. A.: Nepal Ambient Monitoring and Source Testing Experiment (NAMaSTE): emissions of particulate matter from wood- and dung-fueled cooking fires, garbage and crop residue burning, brick kilns, and other sources, Atmos. Chem. Phys., 18, 2259-2286, https://doi.org/10.5194/acp18-2259-2018, 2018.

Jimenez, J. L., Canagaratna, M. R., Donahue, N. M., Prevot, A. S. H., Zhang, Q., Kroll, J. H., DeCarlo, P. F., Allan, J. D., Coe, H., Ng, N. L., Aiken, A. C., Docherty, K. S., Ulbrich, I. M., Grieshop, A. P., Robinson, A. L., Duplissy, J., Smith, J. D., Wilson, K. R., Lanz, V. A., Hueglin, C., Sun, Y. L., Tian, J., Laaksonen, A., Raatikainen, T., Rautiainen, J., Vaattovaara, P., Ehn, M., Kulmala, M., Tomlinson, J. M., Collins, D. R., Cubison, M. J., Dunlea, J., Huffman, J. A., Onasch, T. B., Alfarra, M. R., Williams, P. I., Bower, K., Kondo, Y., Schneider, J., Drewnick, F., Borrmann, S., Weimer, S., Demerjian, K., Salcedo, D., Cottrell, L., Griffin, R., Takami, A., Miyoshi, T., Hatakeyama, S., Shimono, A., Sun, J. Y., Zhang, Y. M., Dzepina, K., Kimmel, J. R., Sueper, D., Jayne, J. T., Herndon, S. C., Trimborn, A. M., Williams, L. R., Wood, E. C., Middlebrook, A. M., Kolb, C. E., Baltensperger, U., and Worsnop, D. R.: Evolution of Organic Aerosols in the Atmosphere, Science, 326, 1525, https://doi.org/10.1126/science.1180353, 2009.

Klein Goldewijk, K., Beusen, A., van Drecht, G., and de Vos, M.: The HYDE 3.1 spatially explicit database of human-induced global land-use change over the past 12,000 years, Global Ecol. Biogeogr., 20, 73-86, https://doi.org/10.1111/j.14668238.2010.00587.x, 2011.

Klimont, Z., Kupiainen, K., Heyes, C., Purohit, P., Cofala, J., Rafaj, P., Borken-Kleefeld, J., and Schöpp, W.: Global anthropogenic emissions of particulate matter including black carbon, Atmos. Chem. Phys., 17, 8681-8723, https://doi.org/10.5194/acp-178681-2017, 2017.

Krotkov, N. A., McLinden, C. A., Li, C., Lamsal, L. N., Celarier, E. A., Marchenko, S. V., Swartz, W. H., Bucsela, E. J., Joiner, J., Duncan, B. N., Boersma, K. F., Veefkind, J. P., Levelt, P. F., Fioletov, V. E., Dickerson, R. R., He, H., Lu, Z., and Streets, D. G.: Aura OMI observations of regional $\mathrm{SO}_{2}$ and $\mathrm{NO}_{2}$ pollution changes from 2005 to 2015, Atmos. Chem. Phys., 16, 46054629, https://doi.org/10.5194/acp-16-4605-2016, 2016.

Kurokawa, J., Ohara, T., Morikawa, T., Hanayama, S., JanssensMaenhout, G., Fukui, T., Kawashima, K., and Akimoto, H.: Emissions of air pollutants and greenhouse gases over Asian regions during 2000-2008: Regional Emission inventory in ASia (REAS) version 2, Atmos. Chem. Phys., 13, 11019-11058, https://doi.org/10.5194/acp-13-11019-2013, 2013.

Lacey, F. and Henze, D.: Global climate impacts of countrylevel primary carbonaceous aerosol from solid-fuel cookstove emissions, Environ. Res. Lett., 10, 114003, https://doi.org/10.1088/1748-9326/10/11/114003, 2015.

Lacey, F. G., Marais, E. A., Henze, D. K., Lee, C. J., van Donkelaar, A., Martin, R. V., Hannigan, M. P., and Wiedinmyer, C.: Improving present day and future estimates of anthropogenic sectoral emissions and the resulting air quality impacts in Africa, Faraday Discuss., 200, 397-412, https://doi.org/10.1039/C7FD00011A, 2017. 
Lamsal, L. N., Martin, R. V., Padmanabhan, A., van Donkelaar, A., Zhang, Q., Sioris, C. E., Chance, K., Kurosu, T. P., and Newchurch, M. J.: Application of satellite observations for timely updates to global anthropogenic $\mathrm{NO}_{x}$ emission inventories, Geophys. Res. Lett., 38, L05810, https://doi.org/10.1029/2010GL046476, 2011.

Lei, Y., Zhang, Q., He, K. B., and Streets, D. G.: Primary anthropogenic aerosol emission trends for China, 1990-2005, Atmos. Chem. Phys., 11, 931-954, https://doi.org/10.5194/acp-11-9312011, 2011.

Lelieveld, J., Klingmüller, K., Pozzer, A., Burnett, R. T., Haines, A., and Ramanathan, V.: Effects of fossil fuel and total anthropogenic emission removal on public health and climate, P. Natl. Acad. Sci. USA, 116, 7192, https://doi.org/10.1073/pnas.1819989116, 2019.

Li, C., McLinden, C., Fioletov, V., Krotkov, N., Carn, S., Joiner, J., Streets, D., He, H., Ren, X., Li, Z., and Dickerson, R. R.: India Is Overtaking China as the World's Largest Emitter of Anthropogenic Sulfur Dioxide, Sci. Rep.-UK, 7, 14304, https://doi.org/10.1038/s41598-017-14639-8, 2017.

Li, M., Liu, H., Geng, G., Hong, C., Liu, F., Song, Y., Tong, D., Zheng, B., Cui, H., Man, H., Zhang, Q., and He, K.: Anthropogenic emission inventories in China: a review, Natl. Sci. Rev., 4, 834-866, https://doi.org/10.1093/nsr/nwx150, 2017a.

Li, M., Zhang, Q., Kurokawa, J.-I., Woo, J.-H., He, K., Lu, Z., Ohara, T., Song, Y., Streets, D. G., Carmichael, G. R., Cheng, Y., Hong, C., Huo, H., Jiang, X., Kang, S., Liu, F., Su, H., and Zheng, B.: MIX: a mosaic Asian anthropogenic emission inventory under the international collaboration framework of the MICS-Asia and HTAP, Atmos. Chem. Phys., 17, 935-963, https://doi.org/10.5194/acp-17-935-2017, 2017 b.

Liang, C.-K., West, J. J., Silva, R. A., Bian, H., Chin, M., Davila, Y., Dentener, F. J., Emmons, L., Flemming, J., Folberth, G., Henze, D., Im, U., Jonson, J. E., Keating, T. J., Kucsera, T., Lenzen, A., Lin, M., Lund, M. T., Pan, X., Park, R. J., Pierce, R. B., Sekiya, T., Sudo, K., and Takemura, T.: HTAP2 multi-model estimates of premature human mortality due to intercontinental transport of air pollution and emission sectors, Atmos. Chem. Phys., 18, 10497-10520, https://doi.org/10.5194/acp-18-104972018, 2018.

Liu, Z., Guan, D., Wei, W., Davis, S. J., Ciais, P., Bai, J., Peng, S., Zhang, Q., Hubacek, K., Marland, G., Andres, R. J., CrawfordBrown, D., Lin, J., Zhao, H., Hong, C., Boden, T. A., Feng, K., Peters, G. P., Xi, F., Liu, J., Li, Y., Zhao, Y., Zeng, N., and He, K.: Reduced carbon emission estimates from fossil fuel combustion and cement production in China, Nature, 524, 335-338, https://doi.org/10.1038/nature14677, 2015.

Lu, Z., Zhang, Q., and Streets, D. G.: Sulfur dioxide and primary carbonaceous aerosol emissions in China and India, 1996-2010, Atmos. Chem. Phys., 11, 9839-9864, https://doi.org/10.5194/acp-11-9839-2011, 2011.

Marais, E. A. and Wiedinmyer, C.: Air Quality Impact of Diffuse and Inefficient Combustion Emissions in Africa (DICE-Africa), Environ. Sci. Technol., 50, 10739-10745, https://doi.org/10.1021/acs.est.6b02602, 2016.

Marais, E. A., Silvern, R. F., Vodonos, A., Dupin, E., Bockarie, A. S., Mickley, L. J., and Schwartz, J.: Air Quality and Health Impact of Future Fossil Fuel Use for Electricity Generation and
Transport in Africa, Environ. Sci. Technol., 53, 13524-13534, https://doi.org/10.1021/acs.est.9b04958, 2019.

Mauzerall, D. L., Sultan, B., Kim, N., and Bradford, D. F.: $\mathrm{NO}_{x}$ emissions from large point sources: variability in ozone production, resulting health damages and economic costs, Atmos. Environ., 39, 2851-2866, https://doi.org/10.1016/j.atmosenv.2004.12.041, 2005.

McDonald, B. C., de Gouw, J. A., Gilman, J. B., Jathar, S. H., Akherati, A., Cappa, C. D., Jimenez, J. L., Lee-Taylor, J., Hayes, P. L., McKeen, S. A., Cui, Y. Y., Kim, S.-W., Gentner, D. R., Isaacman-VanWertz, G., Goldstein, A. H., Harley, R. A., Frost, G. J., Roberts, J. M., Ryerson, T. B., and Trainer, M.: Volatile chemical products emerging as largest petrochemical source of urban organic emissions, Science, 359, 760, https://doi.org/10.1126/science.aaq0524, 2018.

McDuffie, E. E., Hoesly, R., O'Rourke, P., Braun, C., Feng, L., Smith, S. J., Pitkanen, T., Seibert, J. J., Vu, L., Presley, M., Bolt, R., Goldstein, B., and Kholod, N.: CEDS_GBD-MAPS_SourceCode_2020_v1.0, Zenodo, https://doi.org/10.5281/zenodo.3865670, 2020a.

McDuffie, E. E., Smith, S. J., O'Rourke, P., Tibrewal, K., Venkataraman, C., Marais, E. A., Zheng, B., Crippa, M., Brauer, M., and Martin, R. V.: CEDS_GBD-MAPS: Data Snapshot (2014-2015), Zenodo, https://doi.org/10.5281/zenodo.3833935, 2020b.

McDuffie, E. E., Smith, S. J., O’Rourke, P., Tibrewal, K., Venkataraman, C., Marais, E. A., Zheng, B., Crippa, M., Brauer, M., and Martin, R. V.: CEDS_GBD-MAPS: Global Anthropogenic Emission Inventory of $\mathrm{NO}_{x}, \mathrm{SO}_{2}, \mathrm{CO}, \mathrm{NH}_{3}, \mathrm{NMVOCs}$, BC, and OC from 1970-2017 (Version 2020_v1.0), Zenodo, https://doi.org/10.5281/zenodo.3754964, 2020c.

McLinden, C. A., Fioletov, V., Boersma, K. F., Krotkov, N., Sioris, C. E., Veefkind, J. P., and Yang, K.: Air quality over the Canadian oil sands: A first assessment using satellite observations, Geophys. Res. Lett., 39, L04804, https://doi.org/10.1029/2011GL050273, 2012.

McLinden, C. A., Fioletov, V., Shephard, M. W., Krotkov, N., Li, C., Martin, R. V., Moran, M. D., and Joiner, J.: Space-based detection of missing sulfur dioxide sources of global air pollution, Nat. Geosci., 9, 496, https://doi.org/10.1038/ngeo2724, 2016.

MEGAN: The Model of Emissions of Gases and Aerosols from Nature, Version 3.1, available at: https://sites.google.com/uci.edu/ bai/megan/data-and-code (last access: 4 March 2020), 2019.

Meidiana, C. and Gamse, T.: Development of Waste Management Practices in Indonesia, European Journal of Scientific Research, 40, 199-210, 2010.

Mickley, L. J., Jacob, D. J., Field, B. D., and Rind, D.: Effects of future climate change on regional air pollution episodes in the United States, Geophys. Res. Lett., 31, L24103, https://doi.org/10.1029/2004GL021216, 2004.

Moravek, A., Murphy, J. G., Hrdina, A., Lin, J. C., Pennell, C., Franchin, A., Middlebrook, A. M., Fibiger, D. L., Womack, C. C., McDuffie, E. E., Martin, R., Moore, K., Baasandorj, M., and Brown, S. S.: Wintertime spatial distribution of ammonia and its emission sources in the Great Salt Lake region, Atmos. Chem. Phys., 19, 15691-15709, https://doi.org/10.5194/acp-19-156912019, 2019.

Mozurkewich, M.: The dissociation constant of ammonium nitrate and its dependence on temperature, relative hu- 
midity and particle size, Atmos. Environ., 27, 261-270, https://doi.org/10.1016/0960-1686(93)90356-4, 1993.

Nagpure, A. S., Ramaswami, A., and Russell, A.: Characterizing the Spatial and Temporal Patterns of Open Burning of Municipal Solid Waste (MSW) in Indian Cities, Environ. Sci. Technol., 49, 12904-12912, https://doi.org/10.1021/acs.est.5b03243, 2015.

NEI: 2011 National Emissions Inventory (NEI) Data, available at: https://www.epa.gov/air-emissions-inventories/ 2011-national-emissions-inventory-nei-data (last access: 12 December 2020), 2013.

Paulot, F., Jacob, D. J., Pinder, R. W., Bash, J. O., Travis, K., and Henze, D. K.: Ammonia emissions in the United States, European Union, and China derived by highresolution inversion of ammonium wet deposition data: Interpretation with a new agricultural emissions inventory (MASAGE_NH3), J. Geophys. Res.-Atmos., 119, 4343-4364, https://doi.org/10.1002/2013JD021130, 2014.

Philip, S., Martin, R. V., Snider, G., Weagle, C. L., van Donkelaar, A., Brauer, M., Henze, D. K., Klimont, Z., Venkataraman, C., Guttikunda, S. K., and Zhang, Q.: Anthropogenic fugitive, combustion and industrial dust is a significant, underrepresented fine particulate matter source in global atmospheric models, Environ. Res. Lett., 12, 044018, https://doi.org/10.1088/17489326/aa65a4, 2017.

RAQC: Regional Air Quality Council: Summary of State Implementation Plans, available at: https://raqc.egnyte.com/dl/ KZXQmQtFaQ/2019_SIP_Summaries_Update.pdf (last access: 23 January 2020), 2019.

Reyna-Bensusan, N., Wilson, D. C., and Smith, S. R.: Uncontrolled burning of solid waste by households in Mexico is a significant contributor to climate change in the country, Environ. Res., 163, 280-288, https://doi.org/10.1016/j.envres.2018.01.042, 2018.

Sadavarte, P. and Venkataraman, C.: Trends in multi-pollutant emissions from a technology-linked inventory for India: I. Industry and transport sectors, Atmos. Environ., 99, 353-364, https://doi.org/10.1016/j.atmosenv.2014.09.081, 2014.

Saxena, P. and Seigneur, C.: On the oxidation of $\mathrm{SO}_{2}$ to sulfate in atmospheric aerosols, Atmos. Environ., 21, 807-812, https://doi.org/10.1016/0004-6981(87)90077-1, 1987.

Schöpp, W., Klimont, Z., Suutari, R., and Cofala, J.: Uncertainty analysis of emission estimates in the RAINS integrated assessment model, Environ. Sci. Policy, 8, 601-613, https://doi.org/10.1016/j.envsci.2005.06.008, 2005.

Sharma, G., Sinha, B., Pallavi, Hakkim, H., Chandra, B. P., Kumar, A., and Sinha, V.: Gridded Emissions of $\mathrm{CO}, \mathrm{NO}_{x}, \mathrm{SO}_{2}, \mathrm{CO}_{2}$, $\mathrm{NH}_{3}, \mathrm{HC}_{l}, \mathrm{CH}_{4}, \mathrm{PM}_{2.5}, \mathrm{PM}_{10}, \mathrm{BC}$, and NMVOC from Open Municipal Waste Burning in India, Environ. Sci. Technol., 53, 4765-4774, https://doi.org/10.1021/acs.est.8b07076, 2019.

Shindell, D. and Smith, C. J.: Climate and air-quality benefits of a realistic phase-out of fossil fuels, Nature, 573, 408-411, https://doi.org/10.1038/s41586-019-1554-z, 2019.

SMoG-India: Speciated Multi-pollutant Generator, available at: https://sites.google.com/view/smogindia (last access: 28 February 2020), 2019.

South Korea National Institute of Environmental Research: National air pollutants emission service, available at: http:// airemiss.nier.go.kr/ (last access: 15 Janurary 2018), 2016.

Stevens, C. J., Dise, N. B., Mountford, J. O., and Gowing, D. J.: Impact of Nitrogen Deposition on the
Species Richness of Grasslands, Science, 303, 1876, https://doi.org/10.1126/science.1094678, 2004.

Stohl, A., Aamaas, B., Amann, M., Baker, L. H., Bellouin, N., Berntsen, T. K., Boucher, O., Cherian, R., Collins, W., Daskalakis, N., Dusinska, M., Eckhardt, S., Fuglestvedt, J. S., Harju, M., Heyes, C., Hodnebrog, Ø., Hao, J., Im, U., Kanakidou, M., Klimont, Z., Kupiainen, K., Law, K. S., Lund, M. T., Maas, R., MacIntosh, C. R., Myhre, G., Myriokefalitakis, S., Olivié, D., Quaas, J., Quennehen, B., Raut, J.-C., Rumbold, S. T., Samset, B. H., Schulz, M., Seland, Ø., Shine, K. P., Skeie, R. B., Wang, S., Yttri, K. E., and Zhu, T.: Evaluating the climate and air quality impacts of short-lived pollutants, Atmos. Chem. Phys., 15, 10529-10566, https://doi.org/10.5194/acp-15-105292015, 2015.

Streets, D. G., Canty, T., Carmichael, G. R., de Foy, B., Dickerson, R. R., Duncan, B. N., Edwards, D. P., Haynes, J. A., Henze, D. K., Houyoux, M. R., Jacob, D. J., Krotkov, N. A., Lamsal, L. N., Liu, Y., Lu, Z., Martin, R. V., Pfister, G. G., Pinder, R. W., Salawitch, R. J., and Wecht, K. J.: Emissions estimation from satellite retrievals: A review of current capability, Atmos. Environ., 77, 1011-1042, https://doi.org/10.1016/j.atmosenv.2013.05.051, 2013.

TEPA: Taiwan Emission Data System, available at: https://erdb.epa.gov.tw/eng/DataRepository/EnvMonitor/ ReportInspectAirTEDS.aspx?topic1 (last access: 15 January 2018), 2016.

The World Bank: World Development Indicators, available at: http://databank.worldbank.org/data/download/WDI_excel.zip (last access: 15 January 2018), 2016.

Travis, K. R., Jacob, D. J., Fisher, J. A., Kim, P. S., Marais, E. A., Zhu, L., Yu, K., Miller, C. C., Yantosca, R. M., Sulprizio, M. P., Thompson, A. M., Wennberg, P. O., Crounse, J. D., St. Clair, J. M., Cohen, R. C., Laughner, J. L., Dibb, J. E., Hall, S. R., Ullmann, K., Wolfe, G. M., Pollack, I. B., Peischl, J., Neuman, J. A., and Zhou, X.: Why do models overestimate surface ozone in the Southeast United States?, Atmos. Chem. Phys., 16, 1356113577, https://doi.org/10.5194/acp-16-13561-2016, 2016.

UN: World Urbanization Prospects: The 2014 Revision, available at: https://esa.un.org/unpd/wup/CD-ROM/WUP2014_XLS_ CD_FILES/WUP2014-F01-Total_Urban_Rural.xls (last access: 15 January 2018), 2014.

UN: UN World Population Prospects: The 2015 Revision, available at: http://esa.un.org/unpd/wpp/DVD/ (last access: 15 January 2018), 2015.

UN: World urbanization prospects: The 2018 revision, annual percentage of population at mid-year residing in urban areas by region, subregion, country and area, 1950-2050, available at: https: //population.un.org/wup/Download/ (last access: 24 July 2019), 2018.

UN: World Population Prospects 2019: Total population (both sexes combined) by region, subregion and country, annually for 1950 to 2100, available at: https://esa.un.org/unpd/wpp/Download/ Standard/Population/ (last access: 24 July 2019), 2019.

UNFCCC: National Inventory Submissions of Annex I Parties to the UNFCCC, available at: https://di.unfccc.int/ (last access: 12 August 2019), 2019.

US EPA: An inventory of sources and environmental releases of dioxin-like compounds in the US for the years 1987, 1995, and 
2000, US Environmental Protection Agency, Washington DC, USA, EPA/600/P-03/002F, 667 pp., 2006.

US EPA: Criteria Air Pollutants, available at: https://www.epa.gov/ criteria-air-pollutants (last access: 23 January 2020), 2018.

US EPA: National Annual Emissions Trend: 1970-2018, available at: https://www.epa.gov/air-emissions-inventories/ air-pollutant-emissions-trends-data, last access: 26 August 2019.

van der Werf, G. R., Randerson, J. T., Giglio, L., van Leeuwen, T. T., Chen, Y., Rogers, B. M., Mu, M., van Marle, M. J. E., Morton, D. C., Collatz, G. J., Yokelson, R. J., and Kasibhatla, P. S.: Global fire emissions estimates during 1997-2016, Earth Syst. Sci. Data, 9, 697-720, https://doi.org/10.5194/essd-9-697-2017, 2017.

Venkataraman, C., Brauer, M., Tibrewal, K., Sadavarte, P., Ma, Q., Cohen, A., Chaliyakunnel, S., Frostad, J., Klimont, Z., Martin, R. V., Millet, D. B., Philip, S., Walker, K., and Wang, S.: Source influence on emission pathways and ambient $\mathrm{PM}_{2.5}$ pollution over India (2015-2050), Atmos. Chem. Phys., 18, 8017-8039, https://doi.org/10.5194/acp-18-8017-2018, 2018.

Venkataraman, C., Bhushan, M., Dey, S., Ganguly, D., Gupta, T., Habib, G., Kesarkar, A., Phuleria, H., and Raman, R. S.: Indian Network Project on Carbonaceous Aerosol Emissions, Source Apportionment and Climate Impacts (COALESCE), B. Am. Meteorol. Soc., 101, E1052-E1068, 2020.

Wang, S., Zhang, Q., Martin, R. V., Philip, S., Liu, F., Li, M., Jiang, X., and He, K.: Satellite measurements oversee China's sulfur dioxide emission reductions from coal-fired power plants, Environ. Res. Lett., 10, 114015, https://doi.org/10.1088/17489326/10/11/114015, 2015.

Wiedinmyer, C., Akagi, S. K., Yokelson, R. J., Emmons, L. K., AlSaadi, J. A., Orlando, J. J., and Soja, A. J.: The Fire INventory from NCAR (FINN): a high resolution global model to estimate the emissions from open burning, Geosci. Model Dev., 4, 625641, https://doi.org/10.5194/gmd-4-625-2011, 2011.
Wiedinmyer, C., Yokelson, R. J., and Gullett, B. K.: Global Emissions of Trace Gases, Particulate Matter, and Hazardous Air Pollutants from Open Burning of Domestic Waste, Environ. Sci. Technol., 48, 9523-9530, https://doi.org/10.1021/es502250z, 2014.

Zhang, Q., Streets, D. G., Carmichael, G. R., He, K. B., Huo, H., Kannari, A., Klimont, Z., Park, I. S., Reddy, S., Fu, J. S., Chen, D., Duan, L., Lei, Y., Wang, L. T., and Yao, Z. L.: Asian emissions in 2006 for the NASA INTEX-B mission, Atmos. Chem. Phys., 9, 5131-5153, https://doi.org/10.5194/acp-9-5131-2009, 2009.

Zhao, Y., Nielsen, C. P., Lei, Y., McElroy, M. B., and Hao, J.: Quantifying the uncertainties of a bottom-up emission inventory of anthropogenic atmospheric pollutants in China, Atmos. Chem. Phys., 11, 2295-2308, https://doi.org/10.5194/acp-112295-2011, 2011.

Zheng, B., Tong, D., Li, M., Liu, F., Hong, C., Geng, G., Li, H., Li, X., Peng, L., Qi, J., Yan, L., Zhang, Y., Zhao, H., Zheng, Y., He, K., and Zhang, Q.: Trends in China's anthropogenic emissions since 2010 as the consequence of clean air actions, Atmos. Chem. Phys., 18, 14095-14111, https://doi.org/10.5194/acp-18-140952018, 2018.

Zheng, B., Chevallier, F., Yin, Y., Ciais, P., Fortems-Cheiney, A., Deeter, M. N., Parker, R. J., Wang, Y., Worden, H. M., and Zhao, Y.: Global atmospheric carbon monoxide budget 2000 2017 inferred from multi-species atmospheric inversions, Earth Syst. Sci. Data, 11, 1411-1436, https://doi.org/10.5194/essd-111411-2019, 2019. 